\title{
تأثير هنصة جوجل كلاس روم ( Google classroom ) التفاعلية علي بعض نواتج التعلم للمهارات الاساسية في كرة اليد
}

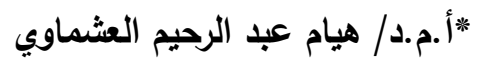

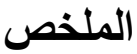

تتاولت هذه الدراسة تأثير إستخدام منصة جوجل كلاس روم ( Google classroom ) علي بعض نواتج التعلم ( التحصيل المعرفي والاداء المهاري في كرة اليد للمهارات قيد البحث ) ، وقد استخدمت الباحثة المنهج التجريبي بتصميم مجموعة واحدة قياس قبلي وبعدي ، وقد بلغ عدد العينة

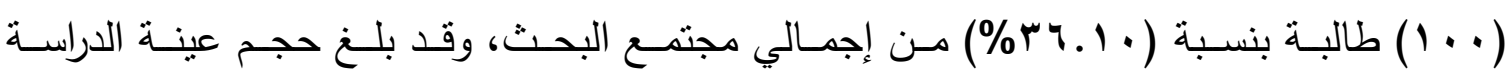

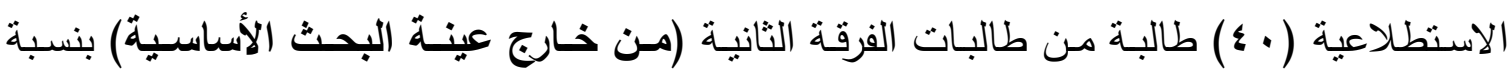
( • ـ ـ ا \% من مجتهع البحث، وبذلك بلـغ إجمالي حجم عينـة الدراسـة الأساسية والاستطلاعية

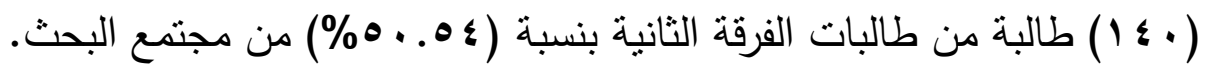
واعتمـت الباحثنة في وسـائل وجمـع البيانـات علـي اسـنطلاع راي الخبـراء واسـتمارتي الاستبيان والاختبارات قيد البحث وكانت من اهم النتائج التي توصلت لها الباحثة تؤثر المنصـات التعليمية

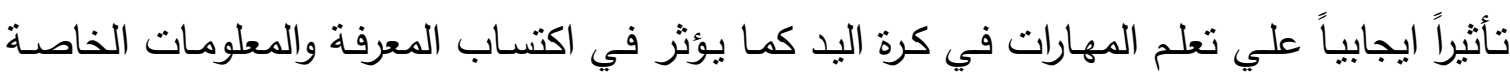
بالمهارات قبد البحث في كرة اليد

الكلمات الرئيسية كرة اليد ؛ المنصة التعليمية التفاعلية ؛ نواتج التعلم " أسناذ مساعد بقسم نظريات وتطبيقات الألعاب الجماعية وألعاب المضرب كلية التربية الرياضية جامعة مدينة السادات 


\section{مقدمة ومشكلة البحث}

نظراً للظروف الغير عاديـة التي يمر بها العالم أجمع في ظل جائحة كورونـا ، أصبحت الحاجـة ملحة لاستغلال التقدم العلمي الهائل في عالم تكنولوجيا المعلومات والاتصالات ، وإيجاد وسيلة فعالة للتواصل للنهوض بالنظم التعليمية من أجل اعداد جيل قادر علي التعلم عن بعد . ويعد التعليم الإككترونـي النمـوذج الجيد الذي يسـتطيع تغييـر شكل التعليم التقليدي في مختلف المؤسسـات التعليميـة ، حيث انـه يعد مـن اهـ التطبيقات التكنولوجيـة الحديثنة التي تهتم بـالتعليم التعاوني والتدريب والتعليم المستمر في مختلف المجالات التعليمبة ، حيث ساعد في حل مشكلات ازدحام المحاضرات ومشكلة الانفجار المعرفي وزيادة الطلب علي التعليم ، والتعليم الاككتروني يعتمد علي طريقة التعليم عن بعد مما ساعد في توسيع فرص القبول في التعليم الامر الذي يساهم في رفع نسبة المتعلمين ، كما يتيح فرصة التعليم في اي وقت وفي اي مكان ، بالإضافة الي انه ساهم في رفع تحصيل الطلاب في المواد المختلفة من خلال تقديم كم هائل من المعلومات والتدرببات التي يتفاعل بها المتعلم مع البرمجيات التعليمية ووجود التغذية المرتدة .(r I: (Y) وقد ساعد إستخدام تكنولوجيا التعليم بطريقة فعالة في حل الكثير من المشكلات التعليمية ، كما انهـ يوفر الكثير من الوقت والجهد حيث أثتبت الأبحاث أهمية الإمكانات التي توفرها تكنولوجيا التعليم في عملية التعليم والتعلم وكيف أنها تساهم بشكل فعال في تحقيق الأهداف التعليمية المختلفة عن طريق جذب انتباه الطلاب نحو المواد الدراسية وتقريب الموضوعات إلى مستوي إدراكهم، وتحسين اتجاههم نحو الموضوعات الدراسية المقدمة. (r ( : • ()) كمـا أن التطور التكنولوجي الهائل سـاعد علي تحسين و تطوير دور المعلم ، الامـر الذي عجل بإمكانية استخدام أسـاليب منتوعة في التعليم تتوائم مع حاجات الطلاب ساعد علي تحقيق اقصي مشاركة للطلاب والتي يجب أن تراعي الفروق الفردية بينهم، والاستجابة لمستويات عليا من الأسئلة

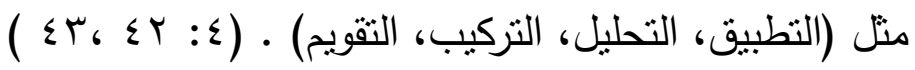

ومع زيادة انتشار استخدام التعليم الالكتروني ظهرت ما تسمي بيئات البيئات التعليمية الإلكترونية، وهي الحيز الذي يتيح عرض المحتوي الإلكتروني للطلاب ويسمح بإدارة عمليات التعلم إلكترونياً بدءاً من تسجيل الطلاب ومروراً بعرض المحتوي والتفاعل معهه وتقيهم أداء الطالب ومدي تعلمهه، 
وكذلك إمكانية التواصل مـع المعلم في أي وقت وأي زمان وتقديم الأنشطة المتتوعة حسب قدرات المتعلمين، كما أن هذه البيئات لا تحتاج إلي متخصصين في البرمجة أو التصميم من أجل التعامل معها، ولكنها تتطلب العديد من الكفايات التي يمكن تتميتها لدي مستخدمي هذه النظم، كما أنها توفر لوحة تحكم تسهل عملية الإدارة، ووجود وسائل دعم متتوعة لكل من المعلم والمتعلم، وتتميز بسهولة تطويرها وتحديثها بطريقة مباشرة وبأقل تكلفة و أقل جهد وتتيح للمتعلم اختيار مستوي التحكم في تعلمهه والتي تتلاءم مـع قدراته وإمكانياته، حيث تسـاعد المتعلم على التقدم في تعلمـه بشكل سـل.

والمنصات التعليمية التفاعلية هي بيئة تعليمية تفاعلية تجمع بين شبكات التواصل الاجتماعي ، وبين أنظمة إدارة المحتوي الاكتروني ، وتعد بيئات آمنة للتواصل والتعاون وتبادل المحتوي وحل الواجبات وإجـراء المناقثـات، وتسـمح للمعلمين بإنثـاء الصـفوف والمجموعـات داخل تلك الصـفوف، وتتيح لأولياء الأمور حسابات خاصـة بهم تمكنهم من متابعة درجات أبنائهم، وتمكن المعلم من التواصل مـع أولياء الأمسور للوقوف على مستوي تقدم أبنـائهم، وإثـعارهم بالواجبات المتأخرة لديهم، وبكافـة

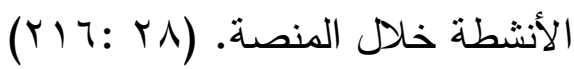
ويظل المعلم في كرة اليد هو العامل الأساسي لتحقيق العملية التعليمية، فإنه مهما بلغت اتجاهات التربية وأهدافها من الطموح ومهما بلغت السياسات التربوية والخطط الموضوعة لتتفيذها من الدقة والوضوح فإن هذه الأهداف وتطبيق تلاك السياسات وتتفيذ تلك الخطط بنجاح تلقي على كاهل معلم

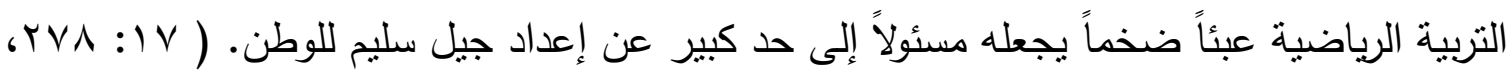

فهذه المسئولية تتطلب مـن معلم رياضـة كرة اليد أن يكـون جديراً بهـا، ذلك عـن طريـق العمـل المتواصل، والتعرف على مـا يطرأ من تغير واستحداث في طرق وأسـاليب التدريس؛ لمواكبـة تلك التغييرات والمستحدثات، حتى تتم عملية التدريس بكفاءة عالية. (7 (: r Y ( ) ومن خـل قيام الباحثة بمسئولياتها التدريسية اتجاه طلابها لتوفير المنـاهج التدريسية مـع مراعاة التباعد الاجتمـاعي والاشتراطات الصحية لمواجهة جائحة كورونـا " كوفيد 9 ا " ، الامر الذي دفع إلي إيجاد حل لهذه المشكلة ، واستغلال التقدم التكنولوجي الهائل وتطور عصر التقنية المعلوماتية 
الذي انعكس بالإيجاب على قدرة الطلاب في استخدام الأجهزة وآليات الاتصال الحديثة من أجهزة الكمبيوتز والأجهزة الذكية وشبكات الإنترنت، وقد لاحظت الباحثة ندرة في تلك الدراسات التي تعمل على تتمية وتطوير المهارات الاساسية في كرة اليد ، الأمر الذي دفع إلي القيام بإجراء الدراسة. ثانياً: - هدف البحث :

يهدف البحث إلى التعرف على تأثير إستخدام المنصـة التعليمية التفاعلية ( جوجل كلاس ) على بعض نواتج التعلم للمهارات الاساسية في كرة اليد لدي طالبات الفرقة الثانية بكلية التربية الرباضية

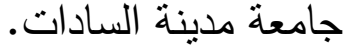
ثالثأ: - -فروض البحث: ا ـ توجد فروق دالة إحصائياً بين منوسط القياس (القبلي، البعدي) لمجموعة البحث التجريبية في مستوي أداء المهارات الاساسية في كرة البد لصالح القياس البعدي. r. توجد فروق دالة إحصائياً بين متوسط القياس (القبلي، البعدي) لمجموعة البحث التجربيية في مستوي التحصيل المعرفي لصالح القياس البعدي. رابعاً: -المصطلحات المستخدمة في البحث: المنصـة التعليميـة التفاعليـة: موقع للتواصل الاجتمـاعي مخصصـة للتعليم، ، وتستخدم فيها تقنيـة الجيل الثاني من الويب، ويتحكم فيها المعلم عن طريـق التواصل مـع الطالبـات من خـلال فضـاء مفتوح يرسل فيه ويستقبل الرسائل النصية والصوتية ويناقش درجاتهم واختباراتهم وواجباتهم وأكثر من

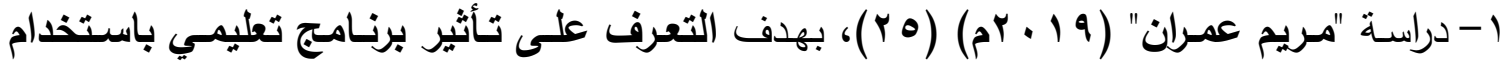
المنصـة التعليميـة التفاعليـة في تعلم بعض المهارات الأساسية بـالكرة في التمرينـات القتبـة الإيقاعية لطالبات كلية التربية الرياضية - جامعة طنطا، استخدمت الباحثة المنهج التجريبي ذو القباس القبلـي البعدي لمجموعـة واحدة، وتمثل مجتمع البحث في طالبات الفرقة الأولي بكلية التربية الرياضية - جامعة طنطا، وكان قوام عينة البحث ( • ( ) طالبة، وكانت أهم النتائج 
تحقيق البرنـامج المقترح باستخدام المنصـة التعليميـة التفاعليـة نتـائج إيجابيـة على مسـتوي التحصيل المعرفي والأداء المهارى واتجاه الطالبات نحو استخدام المنصات التعليمية في التعليم.

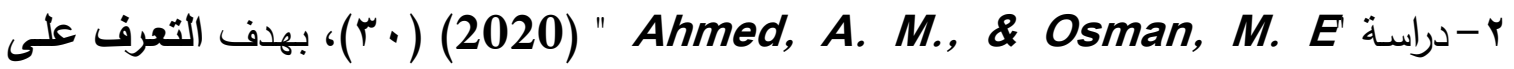
فاعليـة استخدام منصـة WiziQ التفاعليـة على تحصيل الطلاب واتجـاههم نحوهـا، واستخدم الباحثان المنهج التجريبي، وتمثل مجتمع البحث في طلاب "دورة تكنولوجيا التعليم والمعلومات" بكلية التربية - جامعة السلطان قابوس، تكونت عينة البحث من (Y ع) طالباً مسجلين بالدورة تم تقسيمهم إلىى مجموعتين (مجموعـة تجربييـة ومجموعـة ضـابطة) بواقع (Y0) طالبـة للمجموعـة التجربيــة و(V l ) طالبـة للمجموعـة الضـابطة، وكانــت أهـم النتــائج وجـود فـروق ذات دلالــة إحصـائية بين المجموعـة التجريبية والضـابطة في مستوي التحصيل ولصـالح مجموعة البحث التجربية، كما كانت نتائج المجموعة التجربيية إيجابية نحو استخدام منصة WiziQ.

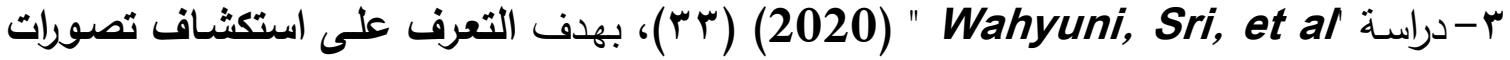
الطلاب لاستخدام المعلم Edmodo في تدريس اللغة الإنجليزية ومساهمتها في تطوير التعلم الأتي، استخدم الباحثون المنهج الوصفي، وتمثل مجتمع البحث في طلاب الثانوية العامة في سيمارانج، جاوة الوسطى، بإندونيسيا، تكونت عينة البحث من (عب) طالباً من مرحلة الثانويـة العامـة، وكاتت أهم النتائج الصورة الإيجابية لمنصـة Edmodo لدى الطلاب حول استخدامها لتسهيل تعلم اللغة الإنجليزية، كما أن Edmodo ساهم بشكل إيجابي في التعلم الذاتي للطلاب حيث كان باستطاعتهم إدارة أنشطة التعلم الخاصـة بهم، واختيار استراتيجيات التعلم المناسبة، وتعزيز الدوافع لديهم.

צ- دراسة ' Ahmed, AL-Rabaani; Fathiya, AL-Wahaib" (2019) (Y)، بهدف التعرف على فاعليـة اسـتخدام المنصـة Edmodo في تعليم مقـرر الجغرافيـا في عمـان، واستخدم الباحثنان المنهج التجريبي، وتمثل مجتمع البحث في طالبات الصف الحادي عثر ، تكونت عينـة البحث من (Or) طالبة تم تقسيمهم إلى مجموعتين (مجموعة تجريبية ومجموعة ضابطة) بواقع (؟Y) طالبة للمجموعة التجريبية و (Y^) طالبة للمجموعة الضابطة، وكانت أهم النتائج أظهر أن استخدام Edmodo زاد بشكل ملحوظ من تحصيل الطالبات. 
ه-دراسـة Ali, Hapid, et al " (2019) (اس)، بهدف التعرف على فاعليـة استخدام Edmodo المنهج التجريبي، وتمثل مجتمع البحث في طلاب كلية الرياضيات والعلوم الطبيعية بجامعة جاروت - قسم الصبدلة، وتكونت عينـة البحث من (OY) طالبـة تم تقسيمهم إلى مجموعتين (مجموعـة تجريبيـة ومجموعـة ضـابطة) بواقـع (rr) طالبـاً للمجموعـة التجريبيـة، ( (r) طالبـاً للمجموعة الضابطة، وكانت أهم النتائج تحسن المهارة والمعرفة لدي الطلاب كما تمكن الطلاب من التفاعل بشكل جيد في كافة الأنشطة لدي المجموعة التجريبية. צ-دراسـة Muanifah, Mahmudah Titi, et al " (2019) (ץ (ب)، بهدف التعرف على تأثير Edmodo في تعلم الرياضيات، استخدم الباحثون المنهج التجريبي ذو القياس القبلي البعـدي لمجموعـة واحـدة ، وتمثل مجتمـع البحث طـلاب المـارس الابتدائيـة في مدينـة جـاوا بإندونيسيا، تكونت عينة البحث من (rV) طالباً تم اختيارهم بطريقة عشوائية، وكانت أهم النتائج فاعلية المنصة Edmodo في تحسين التحصيل لاي الطلبة في الرياضيات. منهج البحث: تحقيقاً لأهداف البحث وفروضـه استخدمت الباحثة المنهج التجريبي نظراً لملاعمته لطبيعة البحث باستخدام التصـيم التجريبي الذي يعتمد على القياس القبلي والبعدي لمجموعـة تجريبيـة واحـدة ( باستخدام المنصة التعليمية التفاعلية ) مجتمع وعينة البحث

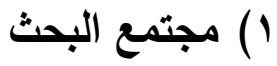

اشتمل مجتمـع البحث على طالبـات الفرقـة الثانيـة بكليـة التربيـة الرياضية - جامعـة مدينـة السـادات

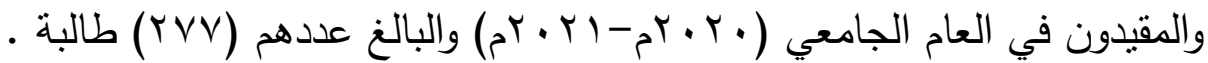
( ) عينة البحث

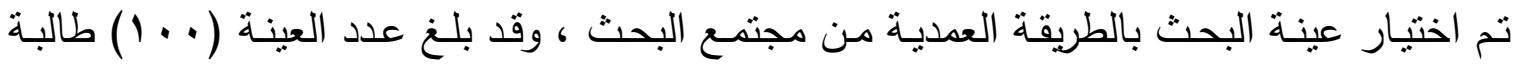

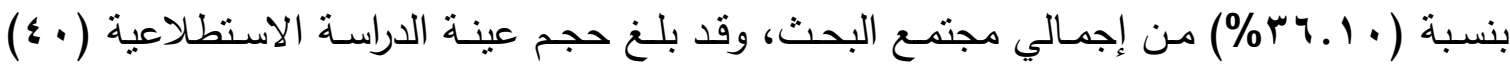
طالبة من طلبة الفرقة الثانية (من خارج عينـة البحث الأساسية) بنسبة ( • ـ ـ (\%) من مجتمع 
البحث، وبذلك بلغ إجمالي حجم عينة الدراسة الأساسية والاستطلاعية ( • ع 1) طالب من طلبة الفرقة التانية بنسبة (ع ه. • 0 \%) من مجتمع البحث. وبائل جمع البيانات

\section{1. ابمقابلات الشخصية}

حيـث قامـت الباحثـة بـإجراء المقابـات الثخصـية مـع السـادة الخبـراء في مجـالي المنـاهج وطـرق

التدريس وتكنولوجيا التعليم مرفق (1). r. المراجع العلمية والدراسات المرجعية

حيث قامت الباحثة بالاطلاع على المراجع العلمية والدراسات المرجعية ذات الصلة بموضوع البحث من حيث دراسـات في مجال استخدام المنصـات التعليمية، دراسـات في مجال الاختبارات المعرفية الالكترونية.

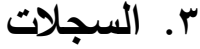

حيث قامت الباحثة بالاستعانة بالسجلات الموجودة في قسم شئون الطلاب، للحصول على البيانات المتعلقة بطالبات أفراد العينة والمتمثلة في طالبات الفرقة الثانية والمقيدون في العام الجامعي • ب · rم - - ب • م، وذلك للتأكد من العمر الزمني ومعرفة الطالبات الباقيات للإعادة والطالبات المستجدات. ع - استمارات استطلاع رأي الخبراء حيث قامت الباحثة باستطلاع رأي السادة الخبراء حول: - - اختبار التحصيل المعرفي ( ) -

- - العناصر البدنية الاكثر ارتباطاً بالمهارات قبد الدراسة مرفق ( ) - الاختبارات التي تقيس العناصر البدنية الخاصة بالمهارات قيد الدراسة مرفق ( V ) - اختبارات المهارات ( قيد الدراسة ) في كرة اليد لطالبات الفرقة الثانية بنات مرفق ( 9 ( ) - التأكد من ملائمة المنصات "للتجربة البحثية"

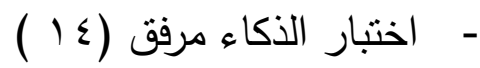
إختبار مستوى التحصيل المعرفي : اتبعت الباحثة الخطوات التالية عند تصميم الاختبار المعرفي : 


\section{تحديد الهدف من الاختبار}

تم تحديد هدف الاختبار الذي اعدته الباحثة بناءاً علي المراجع والدراسات السابقة ورأي الخبراء ، بحيث يهدف الي قياس مسـتوي التحصيل المعرفي للطالبات عينة البحث في المحتوي الدراسي ( توصيف المقرر ) والمتمثل في بعض مواد القانون وتاريخ اللعبة والنواحي المعرفية المتعلقة بالمراحل الفنية والخطوات التعليمية للمهارات قيد البحث . وقد تم التعرف على مستوى التحصيل المعرفي من خلال اتجاهين : قبل البدء في تتفيذ البرنامج ، وذلك عن طريق القياسات القبلية . • بعد الانتهاء من تتفيذ البرنامج ، وذلك عن طريق القياسات البعدية .

تحليل المحتوى الدراسي قامت الباحثة بالاطلاع علي العديد من المراجع العلمية المتخصصة في كرة اليد وذلك للوقوف علي تحليل محتوي المقرر الدراسي الخاص بالفرقة الثانية لطالبات كلية التربية الرياضية - جامعة مدينة السادات حتي يتضمن الاختبار المعرفي الموضوعات الخاصة بالمهارات الخاصة بالعينة قيد البحث. تحديا محاور الاختبار :

استتاداً الي مـا قامـت بـه الباحثة مـن تحليل للمحتوي الدراسي للمهارات قيد البحث في كرة اليد لطالبات الفرقة الثانية من خلال المراجع العلمية والدراسات التخصصية كمـال عبد الحميد ومحمد

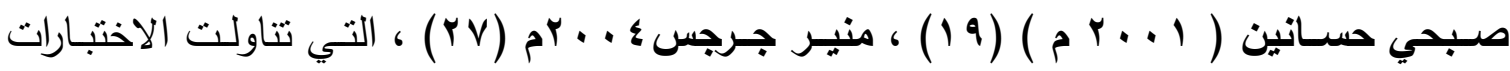
المعرفية توصلت الباحثة الي تحديد محاور الاختبار المعرفي فيما يلي :

$$
\text { r- الاربخ كرة البد }
$$

ب- المهارات الاساسية في كرة البد لعينة البحث ع- بعض مواد قانون كرة اليد ا ـ صياغة مفردات ( أسئلة ) الاختبار قامت الباحثة بصياغة المفردات الخاصة بأسئلة الاختبار المعرفي وذلك بعد الإطلاع على البحوث والدراسات والمراجع العلمية التالية كمال عبد الحميد ومحمد صبحي ( ( . . م م ) ( 9 ) ) أمســين 


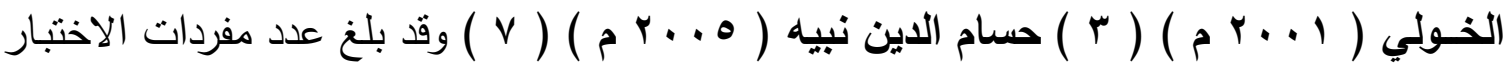
( 7 7 ) مفردة "سؤال" وقامت الباحثة بصياغتها على شكل أسئلة .

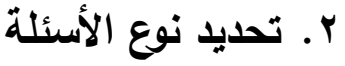

وقع اختيار الباحثة على " نوع الأسئلة " التي أثنارت إليها " بدور المطوع ، سهير بلير " (ج . . rم)

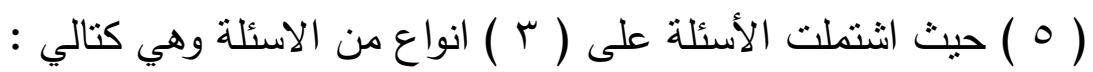
• أسئلة الصواب والخطأ ( ل أو )

وهو من أكثر الأنواع استخداما لسهولة إعداد أسئلته التي يتم اختيارها من المادة المقرة مباشرةً أو بعد إدخال بعض التغيرات الطفيفة على تلك الأسئلة . • أسئلة الاختيار من متعدد

حيث يتم إعطاء الطالب عدد معين من الكلمات أو العبارات التي تتعلق بموضوعٍ ما ليقوم باختيار الكلمات أو العبارات الصحيحة .

• أسئلة التكميل ( إكمال الفراغات بين العبارات )

حيث تُصساغ الأسئلة في صورة عبارات على أن ثُترك فيها مسافات ليكتب فيها الطالب الكلمـة أو

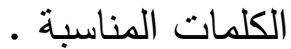
r. - م. إعداد تعليمات الاختبار وضعت الباحثة تعليمات الاختبار بحيث تكون بسيطة وواضحة لدى الطالبة مع بيان لكيفية الإجابة عن الأسئلة ، كما تضمنت تلك الاستمارة البيانات الخاصـة بالطالبة من حيث (الاسم - الصف

$$
\begin{aligned}
& \text { الدراسي - العام الدراسي) . } \\
& \text { ع. مفتاح تصحيح الاختبار : }
\end{aligned}
$$

قامت الباحثة بتصحيح الاختبار بناءاً على الإجابات الصحيحة الخاصـة بأسئة الاختبار وذلك عن طريق حساب درجةٍ واحدة لكل سؤال من أسئلة الاختبار ، وحيث أن مجموع الأسئلة ( 77 ) سؤال فإن النهاية الكبرى للإختبار = ( 77 ) درجة ، حيث يتم تخصيص درجةٍ واحدة لكل إجابة صحيحة ، وصفر للأسئلة المتروكة بدون إجابات أو الإجابات الخاطئة . هـ الصورة المبلئية "الأولى" للإختبار : ( الخبراء ) 
بعد توصل الباحثة للصورة المبدئية للإختبــــار المعرفي والتي بلغت (7 آ) سؤال قامت الباحثـــة بعرض الاختبار في صورته المبدئية ( مُرفق ب ) على عدد (0) خبراء بكليات التربية الرياضية ( مُرفق ( ) بهدف إبداء الرأي حول : • إعادة صياغة أية سؤال من أسئلة الاختبار ـ • إضافة ما يرونه مناسباً من أسئلة . • حذف ما يرونه غير مناسب من أسئلة . • مدى مناسبة نوع الأسئلة التي اشتمل عليها الاختبار م • مدى وضوح تعليمات الاختبار • • مدى ملاعمة مفتاح تصحيح الاختبار وبعد عرض الباحثة للإختبار في صورته المبدئية على الخبراء تم حساب نسبة إطفاق الخبراء على كل مفردة من مفردات الاختبار عن طريق المعادلة التالية :

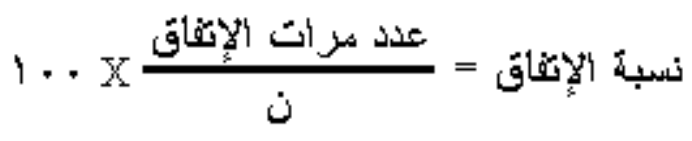

ن= عدد المحكمين (الخبراء)

والجدول التالي يوضِّح نتائج عرض الصورة المبدئية لإختبار التحصيل المعرفي ونسبة إطفاق الخبراء

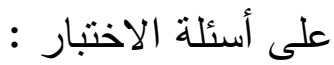

$$
\text { جدول ( ) }
$$

\begin{tabular}{|c|c|c|c|c|}
\hline عدد الأسئلة & إعادة صياغة & نسبة الإتفاق & عدد مرات الإتفاق & رقم السؤال \\
\hline & & $\% \wedge$. & $\varepsilon$ & $r-1$ \\
\hline & & $\% 7$. & $r$ & $\varepsilon$ \\
\hline & & $\% \quad 1 \ldots$ & $\bullet$ & 760 \\
\hline & & $\% \varepsilon$. & $r$ & v \\
\hline & & $\% \wedge$. & $\varepsilon$ & $1 \leq-1$ \\
\hline & & $\%$ & $r$ & 10 \\
\hline & & $\% \quad 1 \ldots$ & • & r \\
\hline & & $\% \leq$. & $r$ & rr \\
\hline
\end{tabular}

نتائج عرض الصورة المبدئية (الصورة الأولى) لإختبار التحصيل المعرفي على الخبراء 


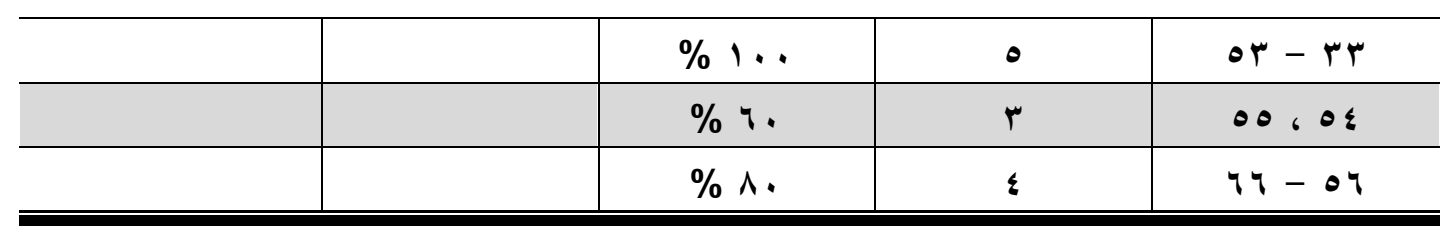

وقد ارتضت الباحثة نسبة إطفاق •^^\% فأكثر من مجموع آراء الخبراء لقبول الأسئلة وبالتالي يتت

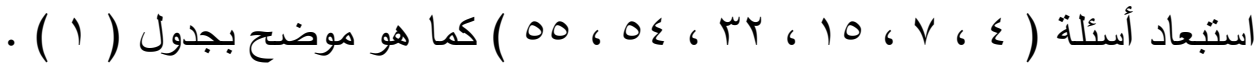
كما جاءت نسبة إطفاق الخبراء على كلٍ من:

مدى مناسبة نوع الأسئلة (من حيث: الصواب والخطأ - الاختيار من متعدد

$$
\begin{aligned}
& \text { - إكمال الفراغات) (بنسبة . . 1\%) . } \\
& \text { مدى وضوح تعليمات الاختبار (بنسبة . . 1\%) . }
\end{aligned}
$$

٪ مدى ملاعمة مفتاح تصحيح الاختبار (من حيث: درجة واحدة للإجابة

الصحيحة ، وصفر للأسئلة المتروكة بدون إجابات أو الإجابات الخاطئة)

$$
\text { . (بنسبة . (1) }
$$

$$
\text { جدول ( ) ( ) ( ) }
$$

\begin{tabular}{|c|c|c|c|c|c|}
\hline التكميل & متعدد من من & الصواب والخطأ & عدد المفردات & المحاور الرئيسية & م \\
\hline 1 & $v$ & r & 1. & تاريخ كرة اليد & 1 \\
\hline 1 & r & - & $r$ & الاعداد البدني & $r$ \\
\hline$v$ & r & $r$ & r & المهارات الاساسية & $r$ \\
\hline$r$ & $\wedge$ & 0 & 17 & القانون & $\varepsilon$ \\
\hline Ir & $\mu_{\Lambda}$ & 1. & 7. & المجموع & \\
\hline
\end{tabular}

توزيع مفردات الاختبار علي نوعية اسئلة الاختبار

التي يتضمنها إختبار التحصيل المعرفي

يتضح من الجدول ( r ) توزيع مفردات الاختبار علي نوعية اسئلة الاختبار المعرفي حيث بلغ عدد اسئلة الصواب والخطأ ( • ( ) اسئلة بينما بلغ عدد اسئلة الاختيار من متعدد (ی؟) سؤال في حين

$$
\text { بلغ عدد اسئلة التكميل ( ا I ) سؤال . }
$$

7 . صورة الاختبار بعد إستطلاع رأى الخبراء "الصورة الثانية للإختبار" 
توصلت الباحثة إلى الصورة الثنانية للإختبار المعرفي ( مُرفق ع ) ، حيث اشتمل الاختبار في صورته الثانية (بعد إستطلاع رأى الخبراء) على ( . ) سؤال . وهى صورة الاختبار التي سيتم تطبيقها على عينة الدراسة الاستطلاعية بهذف التعرف على صلاحية الاختبار (معاملات: السهولة - الصعوبة - التمييز) بالإضافة إلى التعرف على المعاملات

$$
\text { العلمية الخاصة به (الصدق - الثبات) }
$$

V. تحليل مفردات الاختبار (إختبار مدى صلاحية أسئلة الاختبار) للتعرف على مدى صلاحية أسئلة الاختبار قامت الباحثة بتطبيق الاختبار المعرفي على عينة الدراسة الاستطلاعية البالغ عددها (•ع ) وذلك لحساب كلٍ من (معاملات السهولة والصعوبة والتمبيز ) لكل سؤال من أسئلة الاختبار ، كما هو موضح بجدول ( r ) .

$$
\text { جدول (r) (r) (1) ( ) }
$$

\begin{tabular}{|c|c|c|c|c|c|c|c|}
\hline التمبيز & الصعوبة الصعلة & السهولة مُعاملة & السؤال & التمبيز & الصعوبة أمعامل & السهولة مُعامل & السؤال \\
\hline$. Y \leq$ & .09 & . . $\mid$ & r & 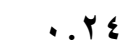 &. .09 &..$\leqslant 1$ & 1 \\
\hline 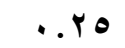 & .0 & .0 & rr & rr. & צr. &. $.7 \varepsilon$ & $r$ \\
\hline..$r o$ & .00 & . . $\leqslant 0$ & r & . Yo & .0 & .0 & $\mu$ \\
\hline rY. & צr. & $.7 \varepsilon$ & &..$r$. & . . &..$Y V$ & $\varepsilon$ \\
\hline$. . Y \leq$ & . . \&1 & .09 & ro & . Yo & . $\leqslant \leqslant 0$ & .00 & 0 \\
\hline$. Y \leq$ & . . \&1 & .09 & rq &.$r$. &..$V r$ &..$Y V$ & 7 \\
\hline$. Y \leq$ & . . \&1 & .099 & $r v$ &.$r r$ & דוr. & .78 & V \\
\hline$. Y \leq$ & .09 & . . \&1 & $\mathrm{r \Lambda}$ &..$r$ & r. &..$Y V$ & $\Lambda$ \\
\hline . ro & .00 & .0 & rq & $. Y \leq$ & .09 & . . \&1 & 9 \\
\hline.$r$. &.$v r$ &..$Y V$ & $\varepsilon$. &..$r$ & . . vr & ..YV & 1. \\
\hline..$r o$ & .00 & . . $\leqslant 0$ & $\& 1$ &..$r$. & ..V &..$Y V$ & 11 \\
\hline.$r_{0}$ & .00 & $\Rightarrow \leqslant 0$ & $\varepsilon r$ &.$r r$ & q & .78 & Ir \\
\hline rr. & צr. & $.7 \leq$ & $\varepsilon r$ & $. Y \leq$ & . . \&1 & .099 & Ir \\
\hline$. Y \leq$ &..$\leqslant 1$ & .009 & $\varepsilon \varepsilon$ &..$r$ &.$v r$ &.$r V$ & $1 \varepsilon$ \\
\hline.$r$. & . .Vr &.$r V$ & $\leq 0$ & $. Y \leq$ & . . \& & .09 & 10 \\
\hline.$r$. & . . v &.$T V$ & $\varepsilon 7$ & .ro & . $\leqslant \leqslant 0$ & .00 & 17 \\
\hline rr. & וr. & $.7 \leq$ & $\varepsilon V$ & .. & ..vr &..$Y V$ & IV \\
\hline
\end{tabular}

معاملات السهولة والصعوبة والتمبيز لإختبار التحصيل المعرفي 


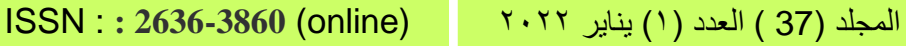

\begin{tabular}{|c|c|c|c|c|c|c|c|}
\hline . Y $\leq \varepsilon$ & . . 1 & .09 & $\varepsilon \Lambda$ & $. Y \leq$ & . . 1 & .09 & 11 \\
\hline.$r$. &..$Y V$ &.$V r$ & $\varepsilon 9$ & & דוr. & .78 & 19 \\
\hline .ro & .00 & . . $\leqslant 0$ & 0 . &.$r$. &.$r V$ &.$v r$ & $r$. \\
\hline..$r$. &..$V r$ &..$Y V$ & 01 & . Yo & .0 & .0 & YI \\
\hline.$r$. & . v &..$r V$ & or &.$r$ &..$Y V$ &.$V r$ & $r r$ \\
\hline . ro & .00 & . $\leqslant 0$ & or & $. Y \leq$ &..$\leqslant 1$ & .009 & $r \mu$ \\
\hline 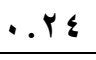 & . . $\leqslant 1$ & .009 & $0 \leq$ &.$r$. & 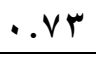 &.$r V$ & $r \varepsilon$ \\
\hline$\not Y \leq$ & . . \&1 & .09 & 00 & r . & דr. & $.7 \leq$ & ro \\
\hline.$r$. &..$Y V$ & 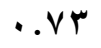 & 07 & r & צr. & .78 & Yq \\
\hline.$r$. &..$Y V$ & . . Vr & ov & . Y & .00 & . . \& & YV \\
\hline . ro & .0 & .0 & $0 \wedge$ & . YO &.$\leq \leqslant 0$ & .00 & rA \\
\hline.$r r$ & דr & $.7 \leq$ & 09 & $. r \leq$ & . . $\leqslant 1$ & .099 & rq \\
\hline..$r$. & . . &..$Y V$ & 7. & . Yo & . $\leqslant \leqslant 0$ & .00 & r. \\
\hline
\end{tabular}

يتضح من الجدول ( r ) أن الاختبار يتميز بمعاملات السهولة بين (

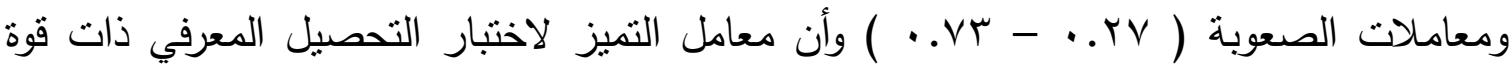

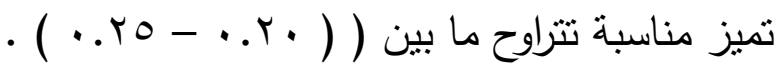
حساب المعاملات العلمية لإختبار التحصيل المعرفي : قامت الباحثة بحساب المعاملات العلمية لإختبار التحصيل المعرفي كالآتي :

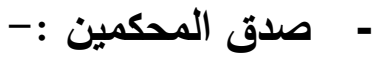

حيث قامت الباحثة بعرض الاختبار علي عدد (0) خبراء بكليات التربية الرياضية مرفق ( (1) ، وقد أثنار الخبراء علي أن الاختبار صادق ويقيس الجوانب التي وضع من أجلها .

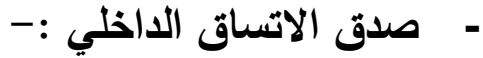

قامت الباحثة بحساب صدق الاختبار علي عينة قوامها (• ع) طالبة من طالبات الفرقة الثانية لإيجاد معامل الارتباط بين درجة كل عبارة ومجموع المحور الذي تتنمي إليه والمجمع الكلي للإختبار 


$$
\text { جدول (飞) }
$$

معامل الارتباط بين درجة كل عبارة ومجموع الدحور الذي تتنمي

ن=: ؛ ؛ عدد الأسئلة =

$$
\text { إليه والمجموع الكلي للإختبار }
$$

\begin{tabular}{|c|c|c|c|c|c|}
\hline المجموع الكلي للإختبار & مع المحل الارتباط & السؤال & 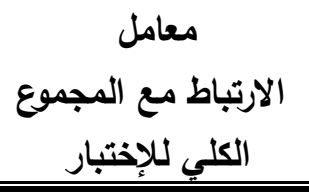 & معامل الارتباط & السؤال \\
\hline$\cdots v \leq q$ & . V०4 & r & . Arr &.$\wedge 9$. & 1 \\
\hline$\cdot . \wedge \wedge \wedge$ & rar & rr &.$V r r$ & $\cdot . \wedge \leq \vee$ & $r$ \\
\hline סז7. & . . $7 \leq \varepsilon$ & $r r$ & $\cdot \wedge 00$ & $\cdot . \wedge 9 \vee$ & $r$ \\
\hline$\therefore \leqslant 1 \wedge$ &..$\leqslant r r$ & $r \varepsilon$ & .941 & .90. & $\varepsilon$ \\
\hline .711 & $.7 \vee \wedge$ & ro & $\cdot . \wedge \vee r$ & $\cdot \wedge \vee \checkmark$ & 0 \\
\hline q & $\therefore \wedge \leqslant 0$ & ד & . Tro & $.7 \vee \wedge$ & 7 \\
\hline$\cdot . \wedge \wedge 1$ & $\cdot . \wedge \wedge \varepsilon$ & $r V$ & $. v \leq r$ & 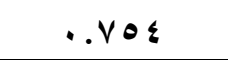 & v \\
\hline. .199 & . 94. & $r \Lambda$ &. .111 & $\cdot . \wedge \leq 0$ & $\Lambda$ \\
\hline 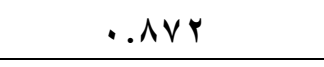 & $\cdot . \wedge \wedge \wedge$ & $r q$ & $. \wedge 0 \leqslant$ & . & 9 \\
\hline$\because \vee \wedge \wedge$ & .V V V V & $\varepsilon$. & $\because \vee \bullet \leq$ & $\because \vee 04$ & 1. \\
\hline$\because v 01$ & $\because \vee \wedge$. & $\leq 1$ & $\cdot . q \cdot r$ & $.91 r$ & 11 \\
\hline$\because V \leq 4$ & $\therefore V 0 \leq$ & $\varepsilon r$ & $.7 Y 1$ & אזד. & ir \\
\hline$\because v \vee$ & $\because \vee \wedge \varepsilon$ & $\varepsilon r$ & . oro & $.0 \leq 1$ & $1 r$ \\
\hline$\therefore \leqslant 70$ &..$\leqslant 7 \wedge$ & $\varepsilon \varepsilon$ & .0 .0 & .011 & $1 \leqslant$ \\
\hline$\therefore \leqslant \leqslant 0$ & .000 & $\leq 0$ & $.9 \times 1$ & $.7 \wedge \varepsilon$ & 10 \\
\hline $.0 \vee 9$ & $.0 \wedge 9$ & $\leq 7$ & .711 &. $.79 V$ & 17 \\
\hline
\end{tabular}

تم حساب معامل ثبات الاختبار بطريقة تطبيق الاختبار وإعادة تطبيقه علي العينة الاستطلاعية والتي تبلغ عددها • ـ طالبة من طالبات الفرقة الثانية وتم تطبيق الاختبار الاول يوم الاثثين الموافق

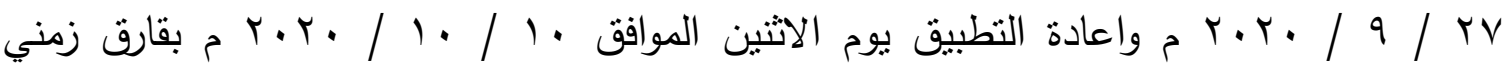
اسبوعين وتم ايجاد معامل الارتباط بين التطبيقين باستخدام معادلة بيرسون. 


$$
\text { جدول ( } 1 \text { ( ) }
$$

معامل الارتباط بين التطبيق الاول والثاني للعينة الاسنطلاعية في اختبار التحصيل المعرفي

\begin{tabular}{|c|c|c|c|c|c|c|}
\hline \multirow{2}{*}{ "ريمة } & \multicolumn{2}{|c|}{ التطبيق الثانى } & \multicolumn{2}{|c|}{ التطبيق الاول } & \multirow{2}{*}{ وحدة القياس } & \multirow{2}{*}{ الاختبار } \\
\hline & $\varepsilon$ & س & $\varepsilon$ & س & & \\
\hline..$\wedge \wedge$ & 1.70 & $T \Gamma . . r$ & 1.57 & TY. $\{\Lambda$ & الدرجة & التحصبل المعرفي \\
\hline
\end{tabular}

يتضح من الجدول ( 7 ) أن اختبار التحصيل المعرفي له درجة ثبات عالية حيث اسفرت النتائج عن وجود ارتباط قوي ذات دلالة معنوية عند مستوي ه .. بين النطبيقين الاول والثناني . صورة الاختبار بعد حساب المعاملات العلمية الخاصة به "الصورة الثالثة والنهائية للإختبار"

في ضوء ما أسفرت عنه الخطوات السابقة والتي تضمنت : • عرض الاختبار على الخبراء بكليات التربية الرياضية • حساب معاملات السهولة والصعوبة والتمييز للإختبار • حساب المعاملات العلمية للإختبار من صدق وثبات

وبناءاً على ما سبق من عرض الاختبار على الخبراء وحساب معاملات السهولة والصعوبة والتمييز بالإضافة إلى المعاملات العلمية ، توصلت الباحثة إلى الصورة الثالثة (النهائية) للإختبار الني سيتم تطبيقها على عينة الدراسة الأساسية .

$$
\text { تحديد زمن الإجابة على الاختبار }
$$

قامت الباحثة بحساب الزمن المناسب للإجابة على إختبار التحصيل المعرفي وذلك أثناء تطبيقه على عينة الدراسة الاستطلاعية من خلال حساب أقل زمن وأكبر زمن ، ويوضِّح الجدول التالي زمن

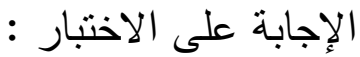


جدول (v)

زمن الإجابة على الاختبار

\begin{tabular}{|c|c|c|c|c|}
\hline \multirow{2}{*}{ متوسط الزمن } & \multirow{2}{*}{ المجموع } & \multicolumn{2}{|c|}{ الزمن التجريبي } & \multirow{3}{*}{ زمن الاختبار } \\
\hline & & أكبر زمن & أقل زمن & \\
\hline هr ق & • • ق & ع & 11 1 ق & \\
\hline
\end{tabular}

يتضح من الجدول رقم (V ) أن متوسط زمن الإجابة على الاختبار هو (0 ق) دقيقة . تحويل الاختبار الورقي إلي إختبار إلكتروني : -

قامت الباحثة باستخدام نماذج جوجل Google forms لتحويل الاختبار المعرفي من صورته الورقية إلي صورته الإكترونية وهو متاح علي الرابط التالي :https://docs.google.com/forms/d/e/1FAlpQLSe6Q1WzMPjqJu1khH_o66iY0 I8sswS8vQ3sPlyhad25prdDeA/viewform المتغيرات والاختبارات قيد البحث تحديا الصفات البذنية الخاصة بلعبة كرة اليد حدد الباحثة الصفات البدنية قيد البحث من خلا الرجوع الي الدراسات والمراجع العلمية ثم قامت بوضعها في استمارة مرفق ( 0 ) روعي فيها الاضافة والحذف بما يناسب راي الخبير وتم عرضها علي ( ) من الخبراء في مجال رياضة كرة اليد مرفق ( (1) وذلك لتحديد أهم هذه الصفات البدنية ومرفق ( 7 ) يوضح اختيارات السادة الخبراء الصفات البدنية التي تم اختيارها وهي :( السرعة الانتقالية - القوة المميزة بالسرعة - تحمل القوة -الدقة - الرشاقة - التوافق - المرونة ) تحديد اختبارات الصفات البدنية قامت الباحثة بإجراء مسح مرجعي للاراسات المرتبطة والمراجع العلمية المتخصصة في مجال رياضة كرة اليد والاختبارات والمقاييس لتحديد الاختبارات التي تقيس الصفات البدنية الخاصة برياضة كرة اليد واستخلص أكثر هذه الاختبارات استخداماً لقياس تلك الصفات البدنية ، ثم قامت بوضعها في إستمارة مرفق (V) روعي فيها الإضافة والحذف بما يناسب رأي الخبير وتم عرضها 
علي (0) من الخبراء في مجال رياضة كرة اليد مرفق (1) ومرفق ( ^ ) يوضح اختيارات السادة الخبراء لاختبارات الصفات البدنية التي تم اختيارها.

$$
\text { ب - الاختبارات المهارية مرفق ( } 9 \text { ( ) }
$$
تحديد الاختبارات المهارية للمهارات قيد البحث :

قامت الباحثة بإجراء مسح مرجعي للاراسات المرتبطة والمراجع العلمية المتخصصة في مجال رياضة كرة اليد لتحديد الاختبارات التي تقيس الأداء المهاري وللمهارات المختارة "قيد البحث" كمال

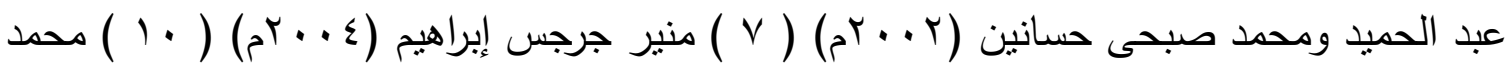
توفيق الليلي ( 1990 م ) ( 1 ) وهي كما يلي: - ( التنطط للكرة- الاستلام والتمرير من الثباتالاستلام والتمرير من الجري - التصويب بخطوة ارتكاز - التصويب بالوثب عالياً ) ثم قامت الباحثة بوضعها في إستمارة مرفق (9) روعي فيها الإضافة والحذف بما يناسب رأي الخبير وتم عرضها علي (0) خبراء في مجال لعبة كرة اليد مرفق (1) لتحديد انسب تلك الاختبارات لطلبة الفرقة الثانبة بالكلية ومرفق ( • ( ) يوضح آراء السادة الخبراء حول أنسب الاختبارات المهارية

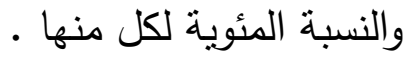

\section{التصميم التعليمي للتجرية البحثية}

في ضوء إطلاع الباحثة على نماذج التصميم التعليمي أمتلة نموذج محمد الهادي ه . ـrم (rr)،

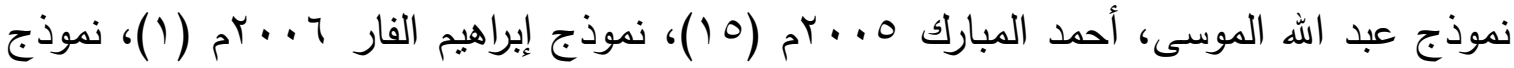

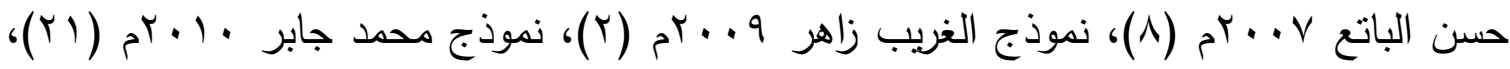

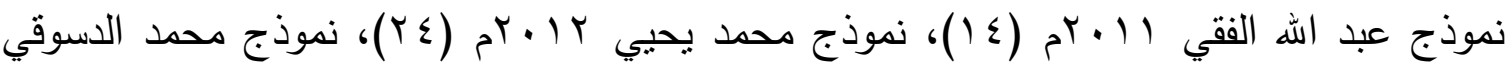

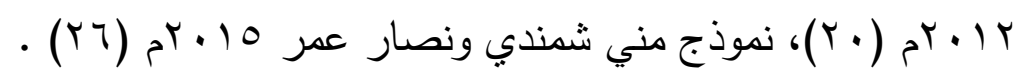
مرحلة التحليل أولاً: -تحليل المشكلة وتقدير الحاجات

تكمن المشكلة في الزيادة المستمرة في أعداد الطالبات ، وكذلك الظروف الاستثنائية التي يمر بها العالم اجمع وبلادنا بصفة خاصة من اجتياج وباء كوفيد 19 " كورونا " الامر الذي دفع القيادة 
السياسية من ضرورة تقليل التجمعات وضرورة ايجاد طرق جديدة للتعلم من خلال المنصات التعليمية ، الأمر الذي دفع الباحثة لاستخدام المنصات التعليمية التقاعلية. ثانياً: -تحليل خصائص المتعلمين وحاجاتهم تمثلت عينة البحث في طالبات الفرقة الثانية بكلية التربية الرباضية - جامعة مدينة السادات حيث يجب اختيار الطالبات الذين تتوافر لديهم متطلبات الدراسة عبر الإنترنت، المتمنلة في امتلاك كل منهم كمبيوتر أو جوال متصل بالإنترنت؛ حتى يتسنى للطالبة التعلم من بعد في أي وقت يناسبها، فضلاً عن توافر بعض مهارات استخدام الكمبيوتر والإنترنت والبريد الإلكتروني لدى هؤلاء الطالبات ، كما يجب أن تتوافر لديهن الرغبة القوية للقيد في دراسة المقرر • ثالثاً: -تحليل الأهداف العامة يتمثل الهدف العام للبحث في التعرف على تأثنر استخدام المنصات التعليمية التفاعلية على بعض نواتج التعلم (المهارات الهجومية في كرة اليد، التحصيل المعرفي ) للطالبات بكلية التربية الرياضية -

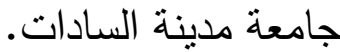
رابعاً: -تحليل بيئة التعلم الإلكترونية ا- قامت الباحثة باستخدام منصة جوجل كلاس روم Google Classroom وذلك للأسباب

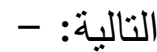

\section{أ- منصة جوجل كلاس روم Google Classroom}

- شبكة تعلم اجتماعية مجانية للمعلمين والطلاب. - بيئتها آمنة ومغلقة بين الطلاب والمعلمين لا مكان فيها لأي مشوش. - المعلم لديه التحكم الكامل، وينضم الطلاب للفصول من خلال دعوتهم من قبل معلمهم فقط. - ولا يتطلب إعداد فصل دراسي افتراضي جديد سوى ثواني. - لا يتم طلب أب معلومات خاصة أثناء التسجيل. - - سهولة الاستخدام، لأن الواجهة شبيهة بالفيس بوك، لذا فهي سهلة ومألوفة للطلاب. - شبكة مخصصة للتعليم، منها نظام رصد الدرجات، وميزة أرشفة الرسائل والاحتفاظ بها كلها. - - توافر تطبيق لها عبر الأجهزة الذكية. 
Yhats App ب تطبيق واتس آب

حيث قامت باستخدام تطبيق واتس آب Whats App وذلك للأسباب التالية: - - تطبيق مجاني متاح لكافة أنظمة تشغيل الأجهزة الذكية. - يستخدمه جميع طالبات عينـة البحث. - مكن استخدامه عبر أجزة الكمبيوتر. - ل لإنشاء مجموعة لكل مدرسة لسهولة للتواصل مع الطالبات.

Google forms نماذج جوجل

حيث قامت الباحثة باستخدام نماذج جوجل Google forms لتحويل ( اختبار الذكاء، اختبار التحصيل المعرفي ) من الصورة الورقية إلى الصورة الاككترونية وذللك للأسباب التالية: - مجانية ومصممة بالأساس للاستنيانات. - - سهولة استخدامه من قبل المحكمين والطلبة.

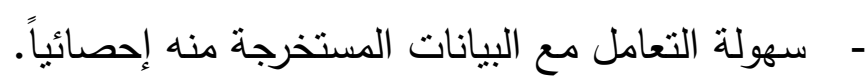
مرحلة التصميم وتتعلق هذه المرحلة بوصف المبادئ النظرية والإجراءات العملية بشكل يكفل تحقيق الأهداف المراد تحقيقها، وتتضمن تلك المرحلة الخطوات التالية: اولاً : -تحديد استراتيجيات التعليم والتعلم استخدمت الباحثة عدد من الاستراتيجيات التعليمية وفقاً لطبيعة المنصة المستخدمة والفئة المستهدفة

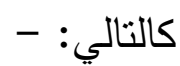
1- استراتيجية التعلم الأتي: حيث قامت الباحثة بإتاحة المحتوي والمادة العلمية (ملفات وورد، ملفات بور بوينت، ملفات فيديو) على منصة جوجل كلاس روم Google Classroom ليتفاعل معها الطالبات في أي وقت وفي أي مكان، الأمر الذي يمكن الطالبات بمتابعة دروسهم بشكل ذاتي مستمر، وبصورة تراعي الفروق

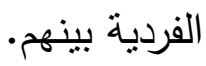
r - استراتيجية التعلم التشاركي: - 
حيث يمكن من خلال منصة جوجل كلاس روم Google Classroom تفاعل الطالبات مع بعضهن ومع المحتوي ومع الباحثة من خلال التعليق وطرح الأسئلة والاستفسارات من قبل الطالبات والإجابة عليها من قبل المعلم والأقران.

ب- استراتيجية المناقشة الإكترونية: حيث قامت الباحثة من خلال المنصة إجراء المناقثة الإلكترونية غير المتزامنة مع الطالبات. ع - استراتيجية التعلم المعكوس :

حيث يتم رفع المحتوي علي منصة جوجل كلاس روم للطالبات قبل ذهابهن للمحاضرات بصورة تمكنهم التفاعل مع المحتوي ومشاهدته أكثر من مرة . ثانياً : - تحديد طبيعة التفاعلات التعليمية تنتوع أنماط التفاعل وتتعدد من خلال المنصنتن، حيث تشتمل على أنماط التفاعل الثالية: 1- التفاعل بين المتعلم وإلمحتوي وذللك من خلا الإبحار داخل منصة جوجل كلاس روم Google Classroom حيث يمكن للطالبات من التفاعل مع المحتوي بمختلف صوره (ملفات وورد، ملفات بور بوينت، ملفات فيديو)، من خلال إضافة التعليقات والاستفسارات على موضوعات المحتوي • r - التفاعل بين المتعلمين ويعضهم وذلك من خلال تفاعل الطالبات مع بعضهم بشكل متزامن وغير متزامن من خلال التعليقات أو

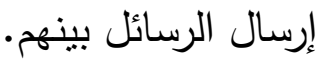
ب- التفاعل بين المعلم والمتطلمين حيث تم ذلك بشكل غير متزامن من خلال النعليقات والرسائل الني تتحها منصة جوجل كلاس روم Google Classroom ثالثاً : -تحديد الانشطة :في ضوء طبيعة البحث تم تحديد الانثطة التي تقوم بها الطالبات وهي كالثالي: 1- تقوم الباحثة بمناقثة الطالبات حول المحتوي المقدم علي المنصة . r-قيام الطابات باداء التدريبات التي تم مشاهدتها علي المنصة . 
ب- التقاعل مع المحتوي، ومع الباحثة ، ومع بعضهم البعض، من خلال التعليقات والرسائل.

$$
\text { 1 إبعا : إنتاج السيناريو التعليمي مع الاختبارات والاستمارات الإكترونية. }
$$

أ- استخدمت الباحثة موقع Google Classroom، لإنتاج المنصة "قبد البحث". استخدمت الباحثة تطبيقي Google Classroom،Whats App كتطبيقات على الأجهزة

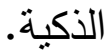
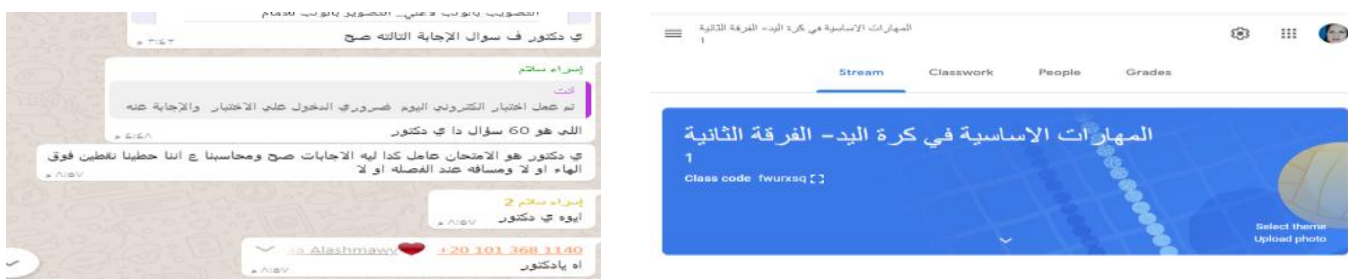

شكل

(1)

Google Classroom، Whats App صورة توضح تطبيقي ب-قامت باستخدام تطبيق واتس آب Whats App للتواصل مع الطالبات .

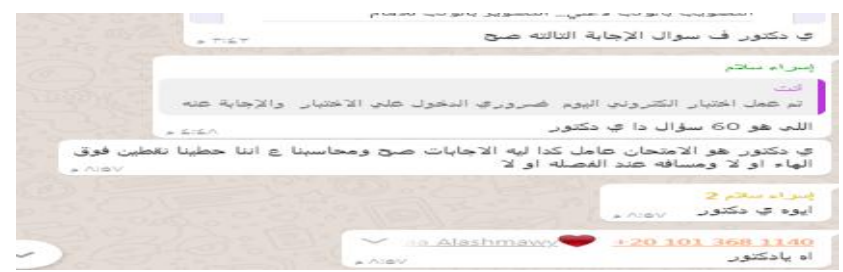

شكل (r)

مجموعات الطلبة على تطبيق وإتس آب Whats App ج- قامت الباحثة بإنشاء قناة على اليوتيوب لرفع الفيديوهات عليها ثم مشاركتها في المنصة.

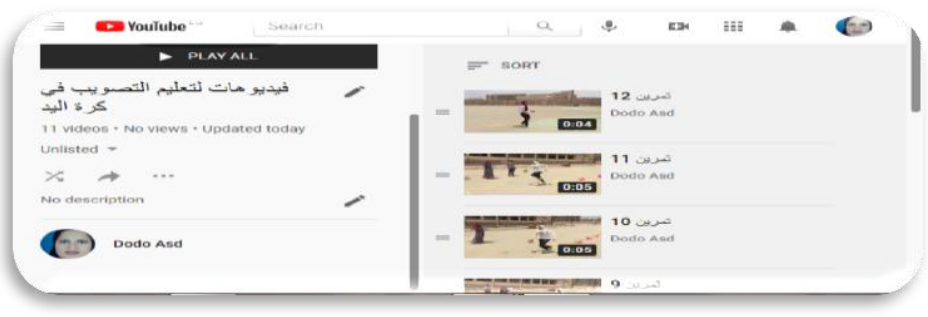

شكل (r) (ب) 


\section{نموذج من قناة الباحثة على اليوتيوب}

د- استخدمت الباحثة نماذج جوجل Google forms لتحويل (اختبار الذكاء مرفق ( \& ( )،

اختبار التحصيل المعرفي ) من الصورة الورقية إلى الصورة الالكترونية مرفق (10).

هـ - استخدمت الباحثة برنامج VSDC Free Video Editor لتحرير الفيديوهات.

$$
\text { r - التصميم الفعلي للمنصة : }
$$

قامت الباحثة باستخدام منصة ، Google Classroom وذلك لتوافر الأدوات بها للقيام بالتجربة البحثية .

أ- ألادوات التي استخدمتها الباحثة في منصة جوجل كلاس روم Google Classroom

$$
\text { أل - ألدات كالتالي: - - إعداد المجلدات }
$$

المجلدات تسنطيع من خلالها إضافة ملفات وإنشاء مجلدات وأيضاً يوجد مجلد المفضلات لحفظ الأشياء المفضلة.

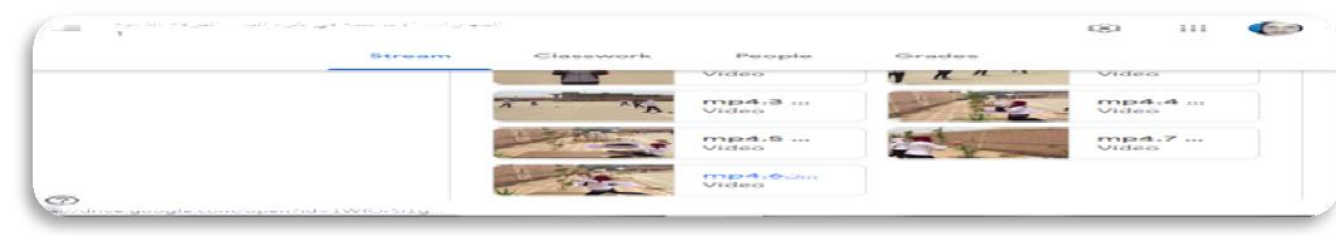

شكل (飞)

أداة إعداد المجلات على منصة جوجل كلاس روم Google Classroom

$$
\text { - - أداة إنشاء الاختبارات الالكترونية }
$$

حيث قامت الباحثة باستخدام تلك الأداة من خلال إنثاء اختبار التحصيل المعرفي الالكتروني "قيد

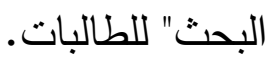

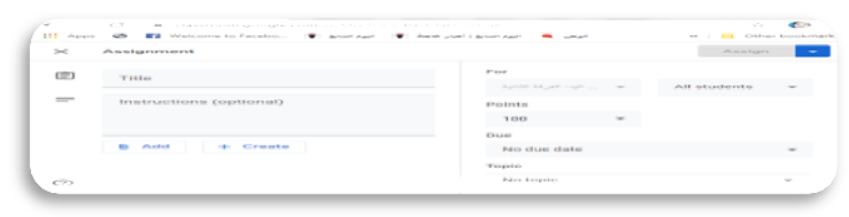

شكل (0) 
أداة إنثاء الاختبارات الاكترونية على منصة جوجل كلاس روم Google Classroom - - - أداة إنثاء الاختبار المعرفي

حيث قامت الباحثة باستخدام نلك الأداة لإنثاء الاحتبار المعرفي التي تضم كافة عينة البحث من

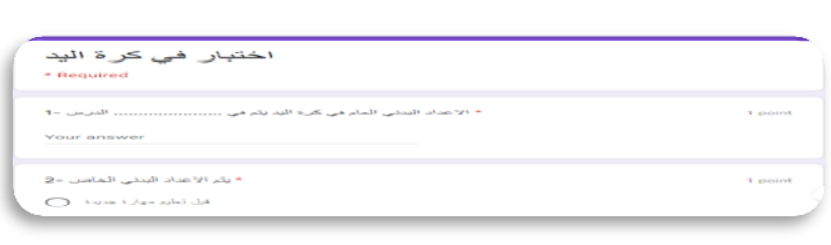

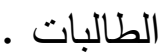

شكل (ד)

أداة اختبار التحصيل المعرفي على منصة جوجل كلاس روم Google Classroom

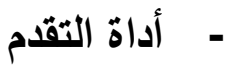
حيث تمكن هذه الأداة من ملاحظة مستوي تقدم الطالب.

$=$

شكل (v)

نموذج من أداء أحد الطلاب في اختبار التحصيل المعرفي

على منصة جوجل كلاس روم Google Classroom

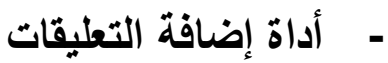

حيث تمكن هذه الأداة من استطاعة الطالبات من التعليق على منشورات المعلم، كذلك تمكن المعلم من الرد عليهم، وكذلك التفاعل بين الطالبات وبعضهم البعض.

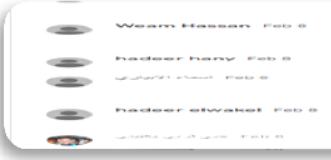

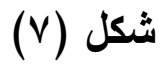


Google نموذج من استخدام أحد الطلاب لأداة إضافة التعليقات على جوجل كلاس روم

Classroom

ثالثاً: -عمليات التقويم البنائي للمنصة التعليمية بعد الانتهاء من إعداد المنصة جوجل كلاس روم Google Classroom ، تم التحقق من صلاحيتهما للنطبيق وذلك من خلال التالي: 1- عرضهما على مجموعة من الخبراء في مجال تكنولوجيا النعليم لإبداء الرأي حول مدي مراعاة المنصة لمعايير تصميم بيئات التعلم الإلكترونية. r- عرضها على مجموعة من الخبراء في مجال المناهج وطرق التدريس لإبداء الرأي حول المحتوي واستراتيجيات التدريس، وأساليب التقويم، وقد أبدي السادة الخبراء بعض الملاحظات التي وضعت في الاعتبار عند إعداد الصورة النهائية لهما مثل (تحويل النصوص في بعض المهارات لفيديو) . r-تجريب المنصة على عدد (•؛) طالبة من عينة البحث الاسنطلاعية، وذللك للتأكد من عدم وجود صعوبات في استخدام أدوات المنصة. خامسا : -الثكل النهائي للمنصة التعليمية بعد الخطوات السابقة أصبحت المنصة جاهزة للنطبيق على عينة البحث الأساسية على الموقع https://classroom.google.com/c/MjY3ODc4NzlzNDc5?cjc=v6svnkc المعاملات العلمية للإختبارات البانية والمهارية والعقلية :

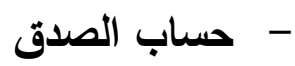
قامت الباحثة بحساب معامل الصدق عن طريق إستخدام صدق التمايز بطريقة المقارنة الطرفية بين الربيعي الأعلي والربيعي الادني ، حيث تم تطبيق الاختبار علي عينة إسنطلاعية قوامها (·ـ) طالبة من الفرقة الثانية ومن خارج العينة الاساسية . 
جدول (^)

دلالة الفروق بين الربيعي الاعلي والادني للإختبارات البدنية والمهارية والعقلية "قيد البحث"

\begin{tabular}{|c|c|c|c|c|c|c|}
\hline \multirow{2}{*}{ | قيمة "ت" } & \multirow{2}{*}{ الفرق بــــا } & \multicolumn{2}{|c|}{ الربيعي الأدني } & \multicolumn{2}{|c|}{ الريبعي الاعلي } & \multirow[b]{2}{*}{ المتغيــــرات } \\
\hline & & $\varepsilon^{ \pm}$ & س س & $\varepsilon^{ \pm}$ & س س & \\
\hline 27.83 & $1 . \leqslant V$ &..$Y Y$ & r. $\varepsilon r$ &..$Y Y$ & $r .9$ & دفع كرة طبية باليدين \\
\hline 11.91 & r.Ar &. .19 & 7.10 & $1 . \varepsilon \varepsilon$ & $1 . .01$ & ثي الجسم للامام من الوقوف \\
\hline 14.18 & 1.19 & .07 & $0 . V T$ &..$Y \varepsilon$ & 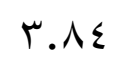 & الجري الزجزاجي بطريقة بارو \\
\hline 12.41 & r.VT &.$r \wedge$ & $7.9 r$ &. .09 & 9.10 & إختبار الدوائر المرقمة \\
\hline 7.82 & r.IT & $1 . \Sigma \wedge$ & V.Vo &.$r$. & $\varepsilon .74$ & اختبار العدو • ب م من البدء عاليا \\
\hline 73.00 &. .71 & $\ldots \wedge$ & I.YT &. .11 & $1 . \wedge \varepsilon$ & اختبار الوثب العريض من الثبات \\
\hline 14.68 & V... & 1.11 & $\varepsilon .9 Y$ & سז. & $11.9 r$ & إختبار التصويب بالكرة علي \\
\hline 37.08 & E.TV &..$\leqslant V$ & T & .0 & $1 \cdot .0$ & التتطط لمسافة · ب م في خط متعرج \\
\hline 24.93 & $0.1 \mathrm{~V}$ & .0 & 7.0 & $1 .+r$ & $11.7 \mathrm{~V}$ & الاستلام والتمرير بطول الملعب \\
\hline 43.12 & 7.0. & 1.11 & $r) . \varepsilon r$ &.$V Y$ & rV.9T & التمرير والاستلام في •r ث \\
\hline 9.38 & $1 . r \varepsilon$ &.$r \wedge$ & $\cdot \cdot 1$ &..$\leqslant 9$ & $1 . \varepsilon Y$ & التصويب بالوثب عالياً \\
\hline 10.65 & Y.OA & 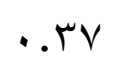 &. $.1 \mathrm{~V}$ &.$V Y$ & 1.10 & التصويب علي المرمي في الزوايا \\
\hline "r.11V & ๕.7. & ( & $\wedge 0 . \Lambda$. &. .01 & $9 . . \varepsilon$. & اختبار الذكاء \\
\hline
\end{tabular}

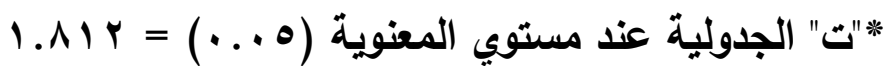

يتضح من جدول (^) أن قيمة "ت" المحسوبة > "ت" الجدولية مما يدل علي أن قيمة "ت" دالة إحصائياً وهذا يثير إلي وجود فروق بين الربيعي الأعلي والادني لصالح الربيعي الأعلي ، مما يدل علي صدق الاختبارات البدنية والمهارية المستخدمة "قيد البحث" لقياس ما وضعت من اجلة .

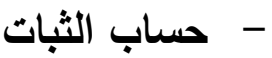

تم حساب ثبات الاختبارات البدنية والمهارية والعقلية بطريقة تطبيق الاختبار وإعادة تطبيقه علي العينة الاسنطلاعية والتي بلغ عددهم (•؛) طالبة من الفرقة الثانية ومن خارج العينة الأساسية ، 
وكانت المدة الفاصلة ما بين التطبيقين (ع () يوم ، وتم إيجاد معامل الارتباط بين التطبيقين ، والجدول التالي يوضح ثبات الاختبارات البدنية .

(9) جدول (9)

معامل الارتباط بين التطبيق الأول والتطبيق الثاني للإختبارات البدنية والمهارية "قيد البحث" ن = . ؛

\begin{tabular}{|c|c|c|c|c|c|c|}
\hline \multirow{2}{*}{ معامل } & \multirow{2}{*}{ المترق بين } & \multicolumn{2}{|c|}{ التطبيق الثاني } & \multicolumn{2}{|c|}{ التطبيق الأول } & \multirow[t]{2}{*}{ المتغيرات } \\
\hline & & $\varepsilon^{ \pm}$ & 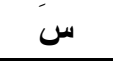 & $\varepsilon \pm$ & س & \\
\hline. .91 & $\cdots r$ & $.9 \mathrm{~V}$ & r.ls & .77 & r.17 & دفع كرة طبية باليدين \\
\hline $.9 \mathrm{~V}$ &.$M r$ & Y..V & 9 & r... & $\wedge .7 \wedge$ & ثتي الجسم للامام من الوقوف \\
\hline $.9 \mathrm{~V}$ & $\cdots r$ &. .79 & $\varepsilon . \wedge r$ &. .71 & $\varepsilon . \wedge \varepsilon$ & الجري الزجزاجي بطريقة بارو \\
\hline.$\wedge 0$ &. .0 &.$v_{1}$ & $\wedge$ &.$\wedge r$ & $v .90$ & إختبار الدوائر المرقمة \\
\hline.$\wedge 0$ & $\cdot \cdot 1$ &. .79 & 0.17 & .99 & 0.10 & اختبار العدو • م م من البدء عاليا \\
\hline.$\wedge \wedge$ &..$r$ &. .19 & 1.7. &.$r V$ & $1.0 \mathrm{~V}$ & اختبار الوثب العريض من التبات \\
\hline. .91 & $\because .9$ & r.ro & ^.\&. & $r . r v$ & A.MI & إختبار التصويب بالكرة علي المستطيلات المتداخلة \\
\hline. .91 & .11 & $1.0 r$ & $\wedge . \vee 7$ & 1.87 & $\wedge .0 \wedge$ & التطط لمسافة ـ م في خط متعرج \\
\hline .94 & מז". & 1.91 & 9.70 & r.r. & q.r. & الاستلام والتمرير بطول الملعب \\
\hline. .91 & $\cdot . r$ & r. & $r \leq . V I$ & Y.A & $Y \varepsilon . \Upsilon \wedge$ & التمرير والاستلام في ، ب ث \\
\hline .991 & $\cdots 9$ & $.7 r$ & 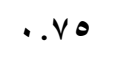 & $\neg V \leqslant$ &.$\wedge \varepsilon$ & التصويب بالوثب عالياً \\
\hline. .91 & $\ldots 0$ & $.7 \mathrm{~V}$ & .90 &.$v r$ & 1 & التصويب علي المرمي في الزوايا \\
\hline$* * .9 \leq r$ & $\ldots r$ & $r . r \wedge$ & $\Lambda V . \diamond V$ & r. $\leqslant \varepsilon$ & AV. & اختبار الذكاء \\
\hline
\end{tabular}

يتضح من جدول (9) أن قيمة " ر" المحسوبة > " ر" الجدولية مما يدل علي أن قيمة " ر" دالة إحصائياً وهذا يشير إلي وجود إرتباط بين التطبيق الاول والتطبيق الثاني وبالتالي ثبات الاختبارات البدنية والمهارية "قيد البحث" مرحلة التطبيق أولاً: -وضع جدول زمني للتطبيق

قامت الباحثة بوضع جدول زمني لتطبيق البرنامج المقترح باستخدام المنصة جوجل كلاس روم Google Classroom 
ثانياً: - -إجراء المقابلات مع الطلاب

قامت الباحثة بإجراء مقابلة مع عينة البحث الأساسية لشرح الفكرة العامة وهدف البحث، وتوجيه الطالبات لإنشاء مجموعات على تطبيق واتس آب Whats App، لاستخدامه في التواصل معهم،

و Google Classroom وإرسال روابط لنروحات كيفية التسجيل في المنصة جوجل كلاس روم وكيفية استخدامهما كطلاب. ثالثاً: -التسجيل الفعلي للطلاب على المنصة ا - التسجيل على المنصة جوجل كلاس روم Google Classroom في ضوء ما سبق قامت الباحثة بإرسال كود المجموعة لعينة البحث الأساسية من خلال تطبيق واتس آب Whats App ، وبعد تأكيد دخول الطالبات على المنصـة ( جوجل كلاس روم Google Classroom ) ، قامت الباحثة بتقسيم الطالبات إلى مجموعات صغيرة باسم كل شعبة. رابعاً: - -إجراء القياسات القبلية قامت الباحثة بإجراء القياسات القبلية لمجموعة البحث التجريبية في اختبار التحصيل المعرفي من خلال لجنة محكمين ، والاختبارات البدنية والمهارية ، في الفترة الاثثين الموافق VY/ 9/ • · • م م

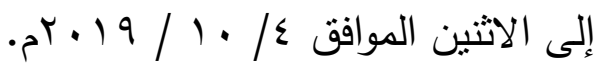

وللتأكد من وقوع عينـة البحث تحت المنحنى الطبيعي وبالتالي التوزيـع الاعتدالي، قامت الباحثة باستخدام درجات القياس القبلي؛ لحساب (المتوسط الحسابي، الوسيط، الانحراف المعياري، معامل الالنواء) لإيجاد الاعتدالية لمتغيرات الدراسة والذي يوضحه جدول ( • (1) جدول (1. (1)

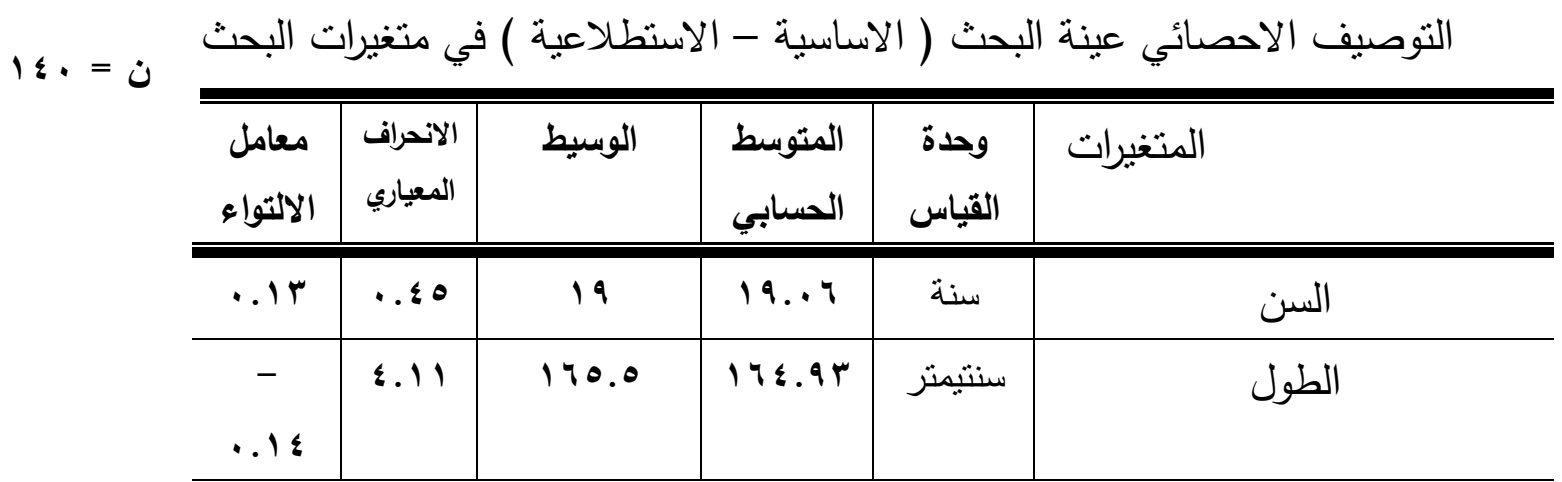


ISSN : : 2636-3860 (online)

$$
\text { المجلد (37 ) العدد ( ) يناير r r. r }
$$

\begin{tabular}{|c|c|c|c|c|c|c|}
\hline $\begin{array}{l}- \\
. . \leq r\end{array}$ & $\{.70$ & 70 & 74.91 & كيلوجرام & \multicolumn{2}{|l|}{ 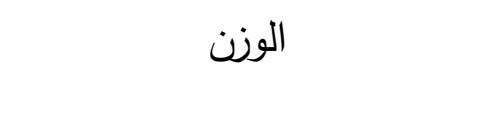 } \\
\hline $\begin{array}{c}- \\
\ldots .0\end{array}$ & 0.01 & 70 & $7 ะ .9 V$ & 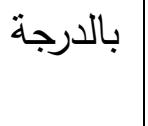 & \multicolumn{2}{|l|}{ الذ الذكاء } \\
\hline . rr & $1.0 r$ & $0 . \varepsilon$ & 0.11 & بالثانية & من اختبار العدو • ب م & الإنتقالية \\
\hline . rr & rד. & r.q & $r .1$. & بالمتر & دفع كرة طبية باليدين & العضلية \\
\hline$\because r$ &.$r_{0}$ & 1.0 & 1.00 & سنتيمتر & العريض من الثبار الوثب & العضلية \\
\hline $\begin{array}{l}- \\
. \text { ro }\end{array}$ &.$\wedge \varepsilon$ & 0 & $\leq . \vee q$ & الثانية & الجري الزجزاجي & الرشاقة \\
\hline$\ldots 7$ & I.VV & $\Lambda .0$ & 1.7 & سنتيمتر & ثني الجسم للامام من & المرونة \\
\hline .19 &. $.9 \mathrm{~V}$ & $\wedge$ & $\Lambda .11$ & الثانية & 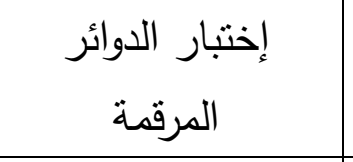 & التوافق \\
\hline$\because r q$ & $r . r 1$ & v & $V .9 Y$ & بالعدد & إختبار التصويب المكرة علي المتداخلة & الاقة \\
\hline $\begin{array}{l}- \\
. . Y^{\prime}\end{array}$ & $1 . \wedge$ & 9 & A.7Yo & الثانية & 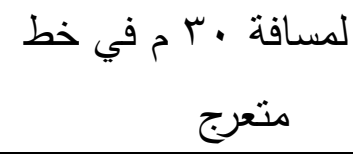 & التنطط \\
\hline $\begin{array}{l}- \\
. .10\end{array}$ & r.IV & 9.0 & $9.1 \vee 0$ & الثانية & والتمرير بطول الملعب & الاستلام \\
\hline $\begin{array}{c}- \\
\ldots .1\end{array}$ & r.Vr & ro & $Y \varepsilon . V V 0$ & العدد & والاستلام في •ب ث & التمرير \\
\hline
\end{tabular}




\begin{tabular}{|c|c|c|c|c|c|}
\hline $\begin{array}{l}- \\
. . r Y\end{array}$ &. .79 & 1 &.$\wedge 0$ & بالعدد & التصويب بالوثب عالياً \\
\hline . &. .79 & 1 & $1 . . r 0$ & بالعدد & التصويب علي المرمي في \\
\hline.$r r$ & 1.90 & Ir & I Y. \&0 & بالدرجة & التحصبل المعرفي \\
\hline
\end{tabular}

يتضـح مـن الجدول ( • ( ) أن معامـل الالتواء في متغيرات ( السـن - الطول - الوزن ) وبعض المتغيـرات البدنيـة والمهاريـة والذكاء والتخصـيل المعرفي يتـرواح بـين (- سع. . بس. • ) أي انحصرت بين (+口 r ) مما بدل علي تجانس أفراد عينة البحث في هذه المتغيرات . مرحلة التقويم

$$
\text { أولاً: - -إجراء القياسات البعدية }
$$

بعد انتهاء التجربة الأساسية قامت الباحثة بإجراء القياسات البعدية لمجموعة البحث التجربيية في

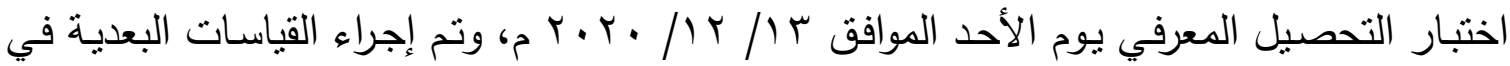

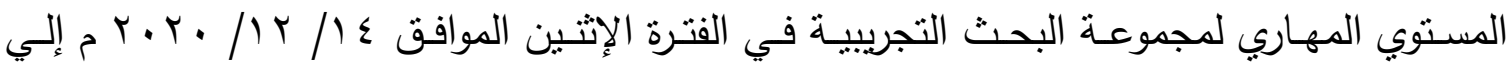

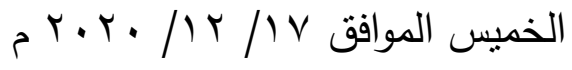

\section{ثانياً: -تحديد المعالجات الإحصائية المستخدمة}

استخدم الباحث المعالجات الإحصائية المناسبة لطبيعة البحث وذلك باستخدام برنامج: حِمة البرامج ، Statistical Package for the Social Science (SPSS) الإحصائية للعلوم الاجتماعية وتم استخدام المعالجات الإحصائية التالية:

$$
\begin{aligned}
& \text { 0- - المتوسط الحسابي. }
\end{aligned}
$$

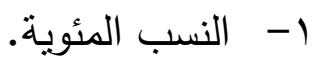

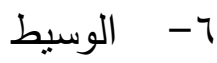

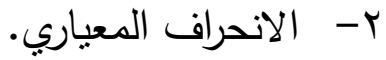

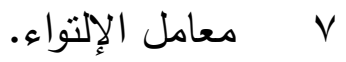

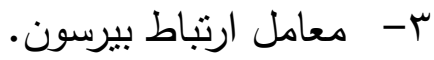

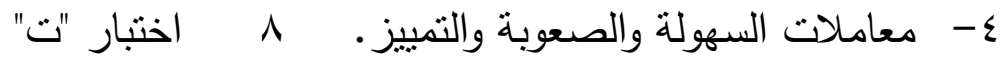




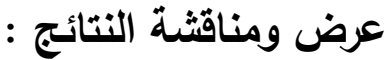

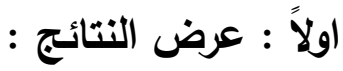

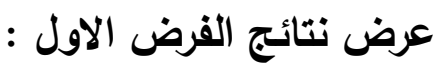

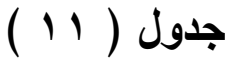

دلالة الفروق بين متوسطي القياس القبلي والبعدي لطالبات الفرقة الثانية للمجموعة التجريبية في 1 ... = الاختبارات المهارية قيد البحث

\begin{tabular}{|c|c|c|c|c|c|c|}
\hline \multirow{2}{*}{ "ت قيمة " } & \multirow{2}{*}{ متوسطين } & \multicolumn{2}{|c|}{ القياس البعدي } & \multicolumn{2}{|c|}{ القياس القبلي } & \multirow{2}{*}{ الاختبار } \\
\hline & & $\varepsilon$ & س & $\varepsilon$ & س & \\
\hline 19.27 & 1.11 & $\cdot .9 \leq$ & $V . \leqslant V$ & $1 . \vee \wedge$ & 1.01 & التنطط لمسافة ب م في خط متعرج \\
\hline $11.7 \leqslant$ & .94 & $1 . \leqslant r$ & $\Lambda . \leqslant Y$ & r.1 & $9.4 \leq$ & الاستلام والتمرير بطول الملعب \\
\hline MI.rr & 1.00 & 0.79 & rT.tr & r.. $q$ & $r \leqslant . T V$ & الاستلام والتمرير في • ب ث \\
\hline 11.87 & $\cdot . \wedge r$ &. .97 & 1.07 &. .70 & . .Ar & التصويب بالوثب عالياً \\
\hline Ir.O1 &.$\wedge$ & 1.14 & $1 . \vee \wedge$ & 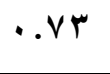 & .911 & التصويب علي المرمي في الزوايا \\
\hline
\end{tabular}

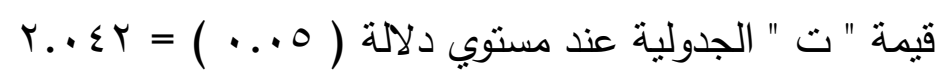

يتضح من الجدول ( 11 ) وجود فروق دالة احصائيا بين منوسطي القياسين القبلي والبعدي

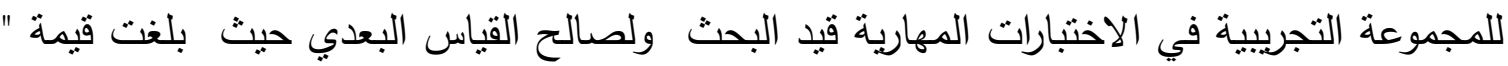

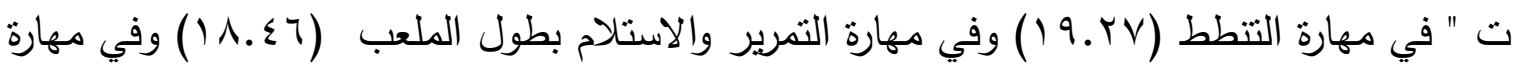

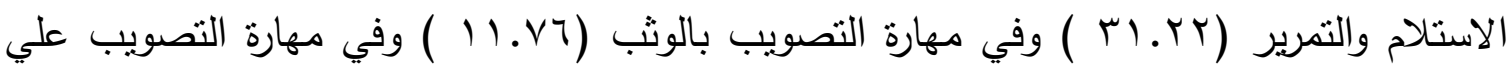

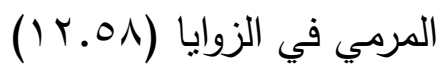

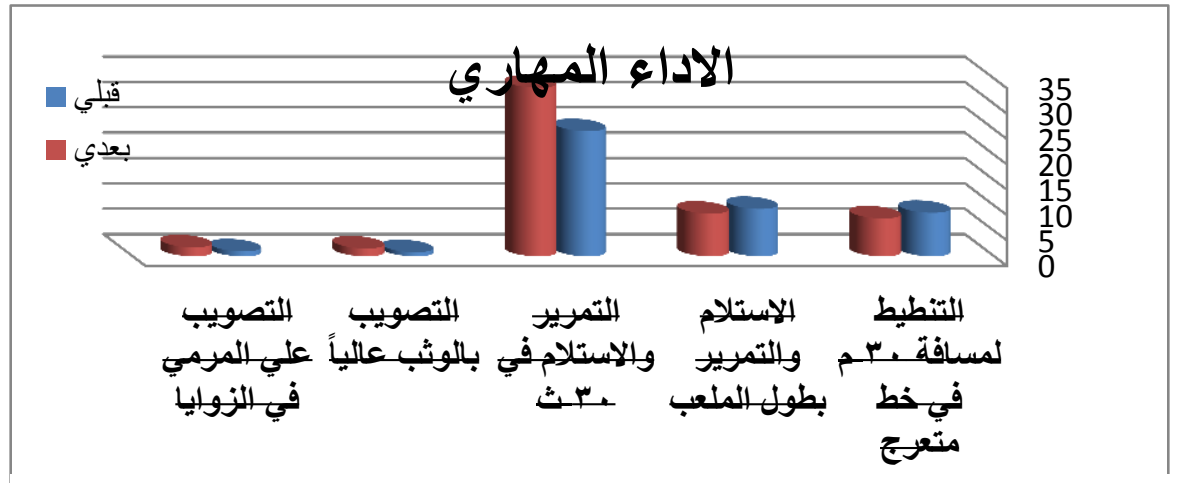

شكل ( 1 ) الفرق بين متوسطات القياس القبلي والبعدي للمجموعة التجريبية

في الاداء المهاري 


\section{جدول ( )}

دلالة الفروق بين متوسطي الفياس القبلي والبعدي لطالبات الفرقة الثانية

$$
\text { للمجموعة التجريبية في التحصيل المعرفي }
$$

\begin{tabular}{|c|c|c|c|c|c|c|}
\hline \multirow{2}{*}{ "قيمة " قات } & \multirow{2}{*}{ متوبطين الفرق بين } & \multicolumn{2}{|c|}{ القياس البعدي } & \multicolumn{2}{|c|}{ القياس القبلي } & \multirow[t]{2}{*}{ الاختبار } \\
\hline & & $\varepsilon$ & س & $\varepsilon$ & س & \\
\hline$\varepsilon V .70$ & TV.ro & $r . . r$ & $\leqslant 9.7 \mathrm{~V}$ & 1.19 & IY.rY & التحصبل المعرفي \\
\hline
\end{tabular}

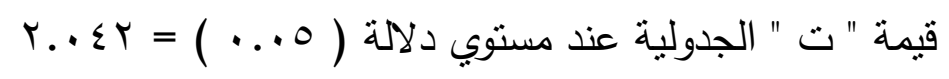

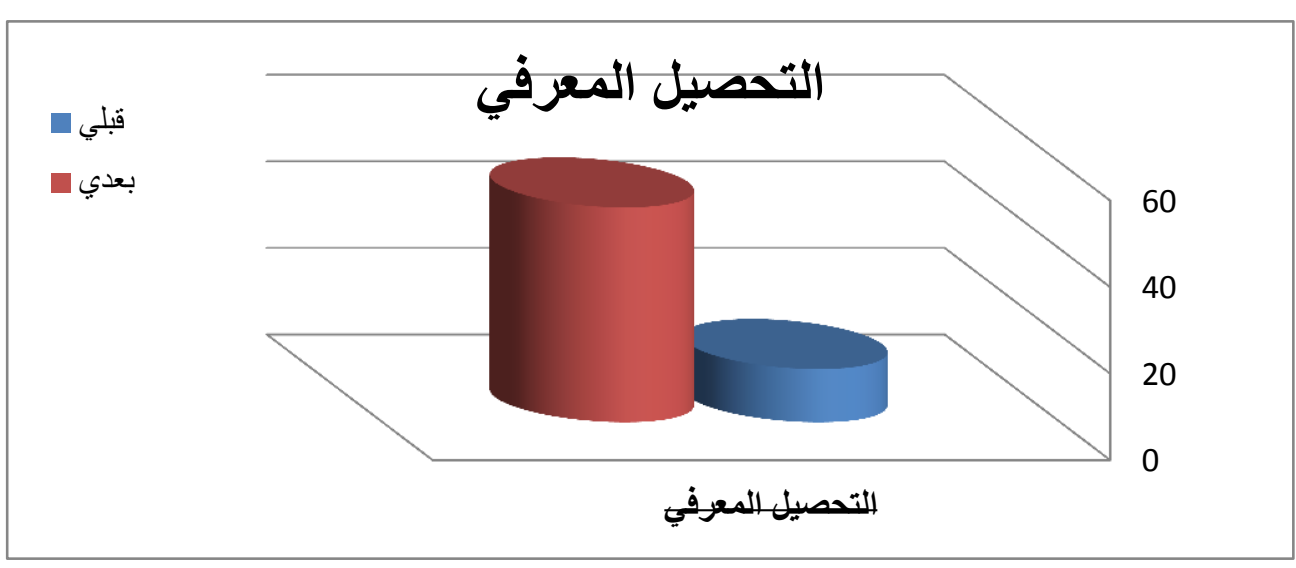

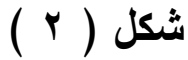

الفرق بين متوسطي القياسين القبلي والبعدي للمجموعة التجريبية في التحصيل المعرفي يتضح من الجدول ( I ) وجود فروق دالة احصائيا بين متوسطي القياسين القبلي والبعدي للمجموعة التجريبية في التحصيل المعرفي قيد البحث ولصالح القياس البعدي حيث بلغت قيمة " ت " في التحصيل المعرفي ( ثانياً : مناقشة النتائج : ا -مناقشة نتائج الفرض الاول :-

ترجع الباحثة أن الفروق بين القياسين القبلي والقياس البعدي للمجموعة التجريبية كما هو موضح بالجدول ( 11 ) ولصالح القياس البعدي الي أن استخدام المنصة في تدريس وتعلم المهارات الاساسية في مجال كرة اليد يعد اسلوب مشوق ومثير لافعية الطلاب لعملية التعلم ويتناسب مع 
طبيعة المرحلة التي نحيا بها في عصرنا الحديث حيث أن ما يتم تقديمه في اسلوب البرمجة بعتمد علي الصورة واستثارة حواس الفرد المتعلم البصرية والسمعية الامر الذي يساعد بشكل ايجابي في تعلم وتطوير الاداء المهاري للفرد المتعلم بشكل يتتاسب مع طبيعة كل فرد كلاً علي حدا ـ كما أن توافر المعارف والمعلومات الخاصة بالمهارات قيد البحث والتي تم تقديمها للفرد بشكل يساعد المتعلم علي اكتساب المعلومات وتثبيتها بشكل جيد . وتري الباحثة أن استخدام المنصة التعليمية في عملية التعلم ساعد الباحثة كثيراً في سرعة استجابة الطالبات للتعلم وكذلك ساعد علي تحسن الاداء المهاري للطالبات بشكل بتتاسب مع طبيعة المرحلة الاستسنائية وكان له اثر ايجابي في اكتساب المعارف والمعلومات الخاصة بتلك المهارات قبد البحث من سرعة استجابة الطالبات للتعلم والمشاركة الايجابية في عملية التعلم مما ساعد الباحثة علي توجيه الطالبات للاخطاء ومعالجتها بشكل اسرع الامر الذي تري فيه الباحثة مناسبة هذه المنصة التعليمية في تعلم المهارات الاساسية في كرة اليد واكتساب المعارف والمعلومات الخاصة بتلك

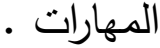
r- - مناقشة نتائج الفرض الثاني ترجع الباحثة أن الفروق بين القياسين القبلي والقياس البعدي للمجموعة التجريبية كما هو موضح بالجدول ( r ) ولصالح القياس البعدي وتري الباحثة أن الاختبارات الإكترونية تعد من أهم الوسائل لقياس الجانب المعرفي كما أصبحت إحدي منطلبات العصر الذي نعيش فيه فمن خلال التقدم والتطور التكنولوجي أصبح لزاماً علينا من التطوير في طرق ووسائل التقويم المختلفة بصفة عامة ومجال التحصيل المعرفي بصفة خاصة .

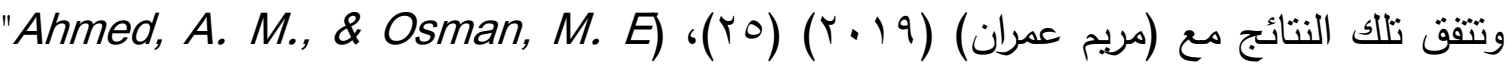
(2020) ( • (r) في كفاءة الاختبارات الإلكترونية في قياس التحصيل المعرفي

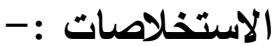
في ضوء البيانات والمعلومات وفي حدود مشكلة البحث وفروض واهداف البحث وفي حدود عينة البحث واستتاداً لمناقثة النتائج توصلت الباحثة الي الاستتناجات التالية :- 
ا ـ تؤثز المنصات التعليمية تأثثراً ايجابياً علي تعلم المهارات في كرة اليد كما يؤثر في اكتساب المعرفة والمعلومات الخاصة بالمهارات قبد البحث في كرة اليد r. يؤثر استخدام استخدام المنصات التعليمية التحصيل المعرفي الخاص بالمهارات قيد البحث.

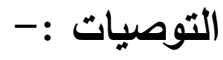

بناء علي النتائج وفي ضوء استخلاصات البحث التي توصلت اليها الباحثنة جاءت التوصيات كما : 1- استخدام المنصة قيد البحث في تعليم المهارات الاساسية في كرة البد . r- الاعتماد علي استثارة المتعلم للتعلم من خلال استخدام حواسه السمعية والبصرية . ب- الاهتمـام بتطـوير عمليـة التعليم باسـتخدام التكنولوجيـة الحديثـة مـن كمبيـوتر ووسـائل سـمعية وبصرية لما لها كبير الاثر في عملية التعلم •

ع - العمل علي ادخال المنصات التعليمية التفاعلية ضمن خطة الدراسة الخاصة بكرة اليد . 0- تعد دورات تدريبية لاعضاء هيئة التدريس والهيئة المعاونة علي كيفية استخدام هذه المصات . 7- اجراء دراسات مشابهة لاستخدام المنصة التعليمية التفاعلية في باقي مهارات كرة اليد .

ا ـ إبراهيم عبد الوكيل الفار (T . . r م): تصميم وبناء المواقع الإلكترونية، تجربة تدربب أعضاء هيئة التدريس بكليات جامعة طنطا على تصميم وإنتاج وتطوير مواقع إلكترونية لمقرراتهم من خلال الويب، المؤتمر والمعرض الدولي الأول لمركز التعلم الإكتروني V- V-9 إبريل.

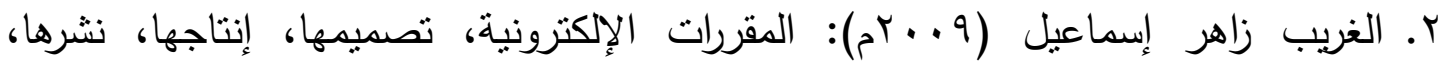
تطبيقها، تقوبمها، دار عالم الكتاب، القاهرة. r. أمين أنور الخولي : اصول التربية البدنية والرياضية ، دار الفكر العربي ، القاهرة ، 1. . . ع. إيمان محمد شعيب (7 ( • rم): أثز اختلاف نمطي الفصول الافتراضية المتزامن/ اللا متزامن على التحصيل وتتمية مهارات إنتاج الألعاب الاككترونية لاي طالبات رياض الأطفال، مجلة العلوم التربوية، المجلد ؟Y، العدد ا، كلية الدراسات العليا للتربية، جامعة 
0. بدور المطوع ، سهير بدير : التربية البدنية "مناهجها وطرق تدريسها" مركز الكتاب - ط ب

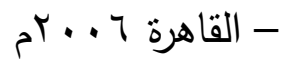

7. جابر عبد الحميد : استراتيجيات التدريس والتعليم ، ط ا ، دار الفكر العربي ، القاهرة ،

V. حسام الدين نبيه : تأثثر استخدام بعض وسائل تكنولوجيا التعليم في تعلم بعض المهارات

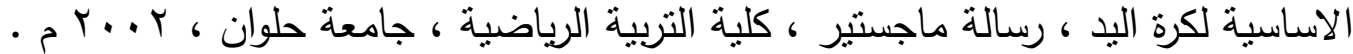
A. حسن الباتع محمد (V . . r م): نموذج مقترح لتصميم المقررات عبر الإنترنت، المؤتمر الدولي الأول لاستخدام تكنولوجيا المعلومات والاتصالات في تطوير التعليم قبل الجامعي في

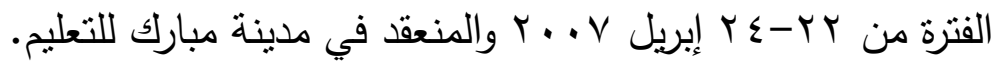
9. خالد حمودة و جلال كمال سالم : الهجوم والدفاع في كرة اليد ، ط ا ، ، دار الكتب ،

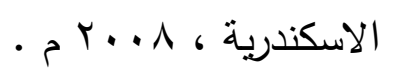

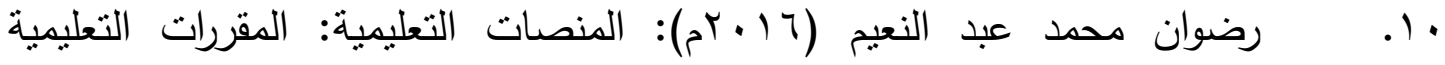
المتاحة عبر الإنترنت، دار العلوم للنشر والتوزيع، القاهرة. ا ا. سلوان خلف الكناني (•r.rم): البرامج التعليمية (الاتجاهات الحديثة التي تقوم عليها واستراتيجياتها رؤية نظرية معرفية وتوظيفية)، مكتبة اليمامة للطباعة والنشر ، بغداد،

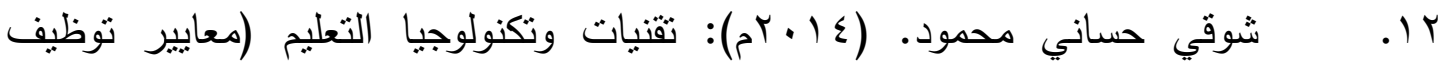
المستحدثات التكنولوجية وتطوير المناهج) ، المجموعة العربية للتذريب والنشر، القاهرة. سا. ـ مارق عبد الرؤوف عامر(10 • بم): التعليم الالكتروني والتعليم الافتراضي (اتجاهات عالمية معاصرة)، المجموعة العربية للتدربب والنشر ، القاهرة. ع ا. عبد الله إبراهيم الفقي (11 • (rم): التعليم المدمج - التصميم التعليمي - الوسائط المتعددة - التفكير الابتكاري، دار الثقافة للنشر والتوزيع، كلية التربية النوعية، جامعة كفر الثيخ.

1 . عبد الله عبد العزيز الموسى، أحمد عبد العزيز المبارك (0.ام): التعليم الإلكتروني الأسس والتطبيقات، مطابع الحميضي، الرياض، السعودية. ا ا. عصام الدين متولي عبد الله (•r.r.rم): الاتجاهات الحديثة لدراسة مناهج التربية الرياضية، مؤسسة عالم لرياضة ودار الوفاء لدنيا الطباعة والنشر ، الإسكندرية. 


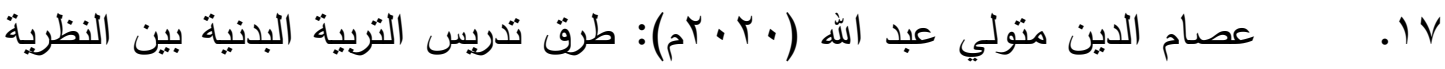
والتطبيق، مؤسسة عالم الرياضة ودار الوفاء لدنيا الطباعة والنشر ، الإسكندرية.

عفاف عبد الكريم حسن : التدريس والتعليم في التربية البدنية والرياضية ( اساليب -

استراتيجيات - تقويم ) ، منشأة المعارف - الاسكندرية ، ـ99 99 م •

9 1. ممال عبدالحميد اسماعيل ، محمد صبحي حسانين : رباعية كرة البد الحديثة ،

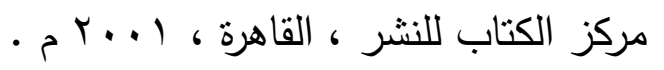

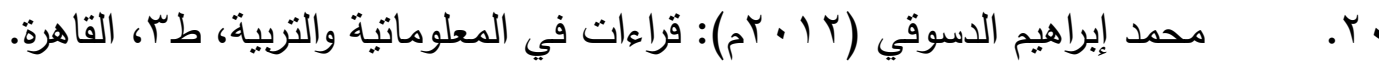

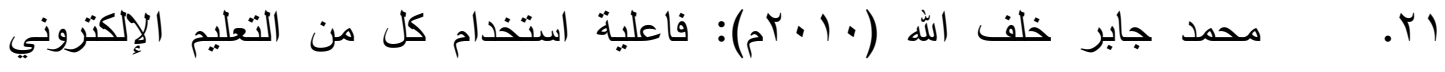
والمدمج في تتمية مهارات إنتاج النماذج التعليمية لدي طلاب تكنولوجيا التعليم، مجلة كلية التربية جامعة بنها، المجلد ا Y، العدد بN، كلية التربية بالدقهلية، جامعة الأزهر . r r. محمد حسن علاوي و كمال عبد الحميد : كرة اليد ، ط ه ، دار المعارف ، القاهرة - 19196

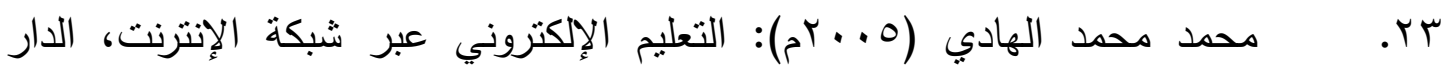
المصرية اللبنانية، القاهرة.

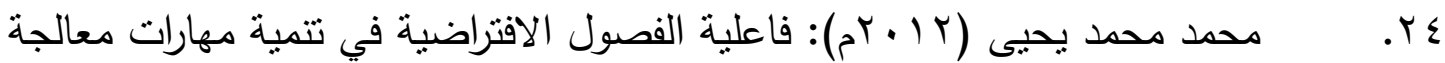
الصور الرقمية لدى طلاب علوم الحاسب بالمملكة العربية السعودية، رسالة ماجستير غير منشورة، معهد البحوث والدراسات العربية، القاهرة.

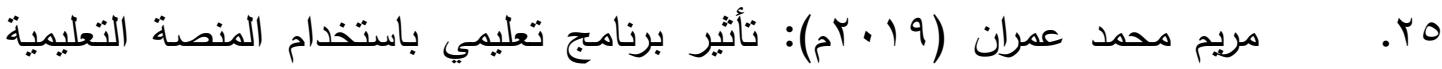
التفاعلية في تعلم بعض المهارات الأساسية بالكرة في التمرينات الفنية الإيقاعية لطالبات كلية التربية الرياضية - جامعة طنطا، رسالة دكتوراه، كلية التربية الرياضية، جامعة طنطا. צr. مني أحمد شمندي، نصار رمضان عمر (10 •rم): التدريب التشاركي عن بعد بمراكز مصادر التعلم (المفاهيم - الأساليب -التطبيقات)، تقديم نصار رضنان عمر، مؤسسة حورس الدولية للنشر والتوزيع.

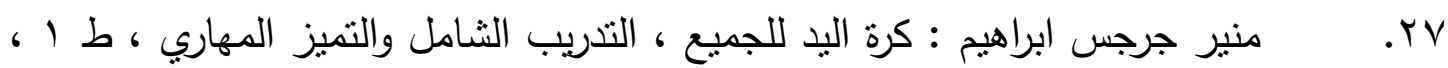

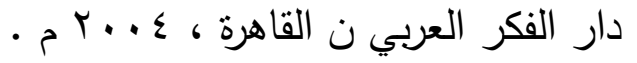

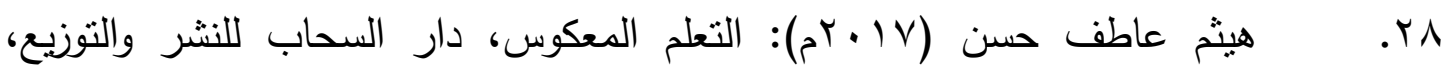




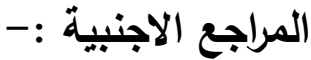

29- Ahmed, A. R., \& Fathiya, A. W. (2019). Female Student Achievement Using Edmodo in the Eleventh-Grade Economic Geography Curriculum in Oman. Journal of Technology and Information Education, 11(1), 38.

30- Ahmed, A. M., \& Osman, M. E. (2020). The Effectiveness of Using WiziQ Interaction Platform on Students' Achievement, Motivation and Attitudes. Turkish Online Journal of Distance Education, 21(1), 19-30.

31- Ali, H., Gojali, D., Darmalaksana, W., Fathonih, A. H., \& Ratnasih, T. (2019, July). The Effectiveness of Using Edmodo as Online Media on Students' Outcome in Reading Course. In 2019 IEEE 5th International Conference on Wireless and Telematics (ICWT) (pp. 1 6). IEEE.

32- Muanifah, M. T., Widodo, S. A., \& Ardiyaningrum, M. (2019, March). Effect of Edmodo towards interests in mathematics learning. In Journal of Physics: Conference Series (Vol. 1188, No. 1, p. 012103). IOP Publishing.

33- Wahyuni, S., Mujiyanto, J., Rukmini, D., Fitriati, S. W., \& Handoyo, B (2020). Integrating Edmodo Into English Instruction: Students' Perceptions And Its Contribution To Autonomous Learning. 